\title{
Novel 3D Structure of Silver Doped ZrO2 Combined Graphene-Based Mesopouros Silica Quaternary Nanocomposite for a Nonenzymatic Glucose Sensing Effects
}

\author{
Won-Chun Oh ( $\nabla$ wc_oh@hanseo.ac.kr) \\ Hanseo University https://orcid.org/0000-0002-0154-7388 \\ Kwang-Youn Cho \\ KICET: Korea Institute of Ceramic Engineering and Technology \\ Saksit Chanthai \\ Khon Kaen University \\ Kamrun Nahar Fatema \\ Hanseo University
}

\section{Research Article}

Keywords: Glucose sensor, Electrocatalytic performance, Functional stability, Interfering agents, Urine

Posted Date: May 27th, 2021

DOl: https://doi.org/10.21203/rs.3.rs-546682/v1

License: (a) (1) This work is licensed under a Creative Commons Attribution 4.0 International License.

Read Full License 


\title{
Novel 3D Structure of Silver Doped $\mathrm{ZrO}_{2}$ Combined Graphene-based Mesopouros Silica Quaternary Nanocomposite for a Nonenzymatic Glucose Sensing Effects
}

\author{
Won-Chun $\mathrm{Oh}^{1), 4) *}$, Kwang-Youn Cho $^{2)}$, Saksit Chanthai ${ }^{3)} \&$ Kamrun Nahar Fatema ${ }^{1)}$ \\ 1) Department of Advanced Materials Science \& Engineering, Hanseo University, \\ Seosan-si, Chungnam, Korea, 356-706 \\ 2) Korea Institutes of Ceramic Engineering and Technology, Soho-ro, Jinju-Si, \\ Gyeongsangnam-do, Republic of Korea \\ 3) Materials Chemistry Research Center, Department of Chemistry and Center of \\ Excellence for Innovation in Chemistry, Faculty of Science, Khon Kaen \\ University, Khon Kaen 40002, Thailand \\ 4) Anhui International Joint Research Center for Nano Carbon-based Materials and \\ Environmental Health, College of Materials Science and Engineering, Anhui \\ University of Science \& Technology, Huainan 232001, PR China
}

\begin{abstract}
:
We described the novel nanocomposite of silver doped $\mathrm{ZrO}_{2}$ combined graphenebased mesoporous silica $\left(\mathrm{ZrO}_{2}-\mathrm{Ag}-\mathrm{G}-\mathrm{SiO}_{2}, \mathrm{ZAGS}\right)$ in bases of low-cost and selfassembly strategy. Synthesized ZAGS were characterized through X-ray diffraction (XRD), scanning electron microscopy (SEM), energy-dispersive X-ray spectrometry (EDX), transmission electron microscopy (TEM), high-resolution transmission electron microscopy (HRTEM), Raman spectroscopy, Nitrogen adsorption-desorption isotherms, X-ray photoelectron spectroscopy (XPS), and Diffuse Reflectance Spectroscopy (DRS). The ZAGS as a enzyme-free glucose sensor active material toward coordinate electrooxidation of glucose was considered through cyclic voltammetry in significant organic electrolytes, such as phosphate-buffer (PBS) at $\mathrm{pH} 7.4$ and

${ }^{*}$ Corresponding author

E-mail: wc_oh@hanseo.ac.kr

Tel: +82-41-660-1337, Fax: +82-41-688-3352
\end{abstract}


commercial urine. Utilizing ZAGS, glucose detecting may well be finished with effective electrocatalytic performance toward organically important concentrations with the current reaction of $9.0 \times 10^{-3} \mathrm{mAcm}^{-2}$ and discovery restrain of $0.05 \mathrm{mmol} / \mathrm{L}$ at the lowest potential of $+0.2 \mathrm{~V}$, thus fulfilling the elemental prerequisites for glucose detecting within the urine. Likewise, ZAGS cathodes can be worked for glucose detecting within the nearness of interferometer substances (e.g., ascorbic corrosive, lactose and starch) in urine at proper $\mathrm{pH}$ condition. Our results highlight the potential usages for subjective and quantitative electrochemical investigation of glucose through the ZAGS sensor for glucose detecting stage permitted within the urine concentration.

Keywords: Glucose sensor; Electrocatalytic performance, Functional stability, Interfering agents, Urine.

\section{Introduction}

Biosensors are created for giving symptomatic data as it were for the patient's prosperity status. Up to presently, all sorts of explanatory strategies, counting electrochemistry, fluorescence, colorimetry, photoelectrochemistry and chemical luminescence, have been received for chemical free glucose discovery. [1,2]. Among distinctive strategies accessible for detecting of glucose level, electrochemical detecting method based upon coordinate glucose electro-oxidation has gotten critical acknowledgment over the past few a long time due to its tall affectability, moo restrain of detecting, promising reaction time, and moo fetched [3]. As clarified already [4], the instrument of coordinate glucose oxidation on the sensor is dependable for the chemisorption of the hydroxyl group onto the metal catalyst and shaping the bond among the d-electron of metal and glucose atom. The oxidation state of glucose particle is effect to the metal surface as well as metal-glucose interaction, lower glucose-metal bond quality and desorption of glucose particles. Another conceivable clarification depends upon the Beginning Hydrous Oxide/Adatom Arbiter (IHOAM), which demonstrates and proposes a pre-monolayer strategy of $\mathrm{OH}_{\mathrm{ads}}$, and that intervene the oxidation of glucose [5]. By considering a imitating method of enzyme-like component, a few metals and metal oxides like $\mathrm{Au}$ [6], Pt [7,8], $\mathrm{Cu}$ [9-12], Ni [13-15], Mn [16,17], Co [18,19], and Fe $[20,21]$ have been detailed. Although the advantage of catalytic action and electron 
exchange is displayed, operation within the strongly soluble condition is not viable for most physiological examples. To realize the regularly picomolar (pM) constrain of discovery (LOD) for the organic analyte, the distinctive nanomaterials considered [22]. Graphene has gotten around the world consideration for the improvement of biosensors for the reason that graphene-based biosensors have high electron exchanges rates, high charge-carrier versatility, and low electrical claude levels are extremely significance for profoundly delicate discovery of organic tests as biomarkers owing to their extraordinary electrochemical (amperometric, voltammetry, impedimetric) characteristics [23,24]. In addition, graphene shows a tall thickness of edge-plane-like imperfection destinations, giving numerous dynamic destinations for electron exchange to chemical and natural species [23]. Graphene containing zirconium oxide $\left(\mathrm{ZrO}_{2}\right)$ offers a solid way to upgrade their application by empowering flexible and tailor-made electrochemical properties, extraordinary potential applications within the broad fields of catalysis. [25-30]. The affectability and conductivity of graphene may be advance upgraded by enhancing Ag NPs owing to their high quantum electron exchange and catalytic properties for modifiers in biosensors [31,32]. Biocompatibility, nontoxicity, high conductivity, chemical and steadiness of $\mathrm{SiO}_{2}$ make to idealize for utilization as busters for adsorption, catalysis, chemical divisions, biosensors [33,34]. With persuaded these points, we created the ZAGS which effectively synthesized by means of self-assembly strategy. $\mathrm{ZrO}_{2}, \mathrm{G}$ and $\mathrm{SiO}_{2}$ have octahedral coordination, $\mathrm{Ag}$ consolidation occupies the opening requested destinations whereas $\mathrm{ZrO}_{2}-\mathrm{G}_{-} \mathrm{SiO}_{2}$ displays within the completely filled layer, giving inexhaustible dynamic localization and various pathways for conceivable charge transport to electrolyte [35,36].

One another idea about created the protein glucose oxidizer based HRPGOD/GPTMS/ CS/Au biosensor for the assurance of glucose the current reaction was 6.0 $\times 10^{-6} \mathrm{Acm}^{-2}$ in $0.1 \mathrm{mmol} / \mathrm{L}$ glucose, which is the assurance of glucose extended from 1 to $351 \mu \mathrm{mol} / \mathrm{L}$ with a discovery restrain of $0.3 \mu \mathrm{mol} / \mathrm{L}$ [37]. In this consideration, $\mathrm{ZrO}_{2-}$ $\mathrm{Ag}-\mathrm{G}-\mathrm{SiO}_{2}$ (ZAGS) nanocomposite was main active material as electrocatalyst for glucose oxidation. $\mathrm{ZrO}_{2}-\mathrm{Ag}-\mathrm{G}-\mathrm{SiO}_{2}$ was effectively synthesized through by utilizing a basic, low-cost, self-assembly strategy, and was inspected for nonenzymatic glucose oxidation for the quick response. The created catalytic composite shows an especially 
high effectiveness for glucose oxidation counting an greatly low working potential of as it were $0.2 \mathrm{~V}$ vs $\mathrm{Ag} / \mathrm{AgCl}$ with prevalent affectability of $9.0 \times 10^{-3} \mathrm{mAcm}^{-2}$, a wide straight extend of 0.05 to $0.35 \mathrm{mmol} / \mathrm{L}$ for glucose sensing, a low discovery restrain of $0.05 \mathrm{mmol} / \mathrm{L}(\mathrm{S} / \mathrm{N}=3)$, an significant steadiness, and a high selectivity within the nearness of interferometer species. In general, $\mathrm{ZrO}_{2}-\mathrm{Ag}-\mathrm{G}_{-} \mathrm{SiO}_{2}$ affirmed a significant catalytic execution in unbiased media without any electron facilitator, provoking to a novel headway for glucose detecting within the urine. The electrochemical detecting behavior of the $\mathrm{ZrO}_{2}-\mathrm{Ag}-\mathrm{G}-\mathrm{SiO}_{2}$ (ZAGS) anode towards glucose detecting was examined utilizing amperometric techniques and is displayed within the taking after segments.

\section{Experimental}

\subsection{Materials}

All chemicals used analytical grade without further refinement. Graphite powder (99 \%), zirconium (IV) isopropoxide (70 wt\% in 1-Propanol), Pluronic F127 were purchased from Sigma Aldrich. Ethylene Glycol, $\mathrm{AgNO}_{3}, \mathrm{HCl}$, Phosphate Buffer, $\mathrm{NaOH}$, $\mathrm{KOH}$, Ethylene Glycol were purchased from Dae-Jung Chemical Korea. Deionized water $\left(18.2{\left.\mathrm{M} \Omega \mathrm{cm}^{-1}\right)}^{-1}\right.$ was self-made product.

\subsection{Synthesis of $\mathrm{ZrO}_{2}$}

In the first step, $6.5 \mathrm{~g}$ of Pluronic F127 was broken up in $30.5 \mathrm{ml}$ of ethanol (Solution A). At that point $30.5 \mathrm{ml}$ of the zirconium (IV) isopropoxide solution was included in $30.5 \mathrm{ml}$ of ethanol and ethylene glycol separately, utilized as a stabilizer (Solution B) with vigorous mixing. At that point, the B was included within the A. The final obtained solution was mixed at $314 \mathrm{~K}$ taken after by including dropwise $20.5 \mathrm{ml}$ of $\mathrm{H}_{2} \mathrm{O}$ to this blend. Hydrochloric corrosive was included to alter the $\mathrm{pH} 2.4$. At that point blended at $314 K$ for $1 \mathrm{~h}$ and kept at $354 K$ in a closed measuring utensil for $24 \mathrm{~h}$. At that

point sifted and dried at $374 \mathrm{~K}$. The synthesized tests were at that point calcined at $674 \mathrm{~K}$ for $5 \mathrm{~h}$ to dispose of the format. To evaluate warm steadiness, tests without the format were calcined at $874 K$ for $5 \mathrm{~h}$.

\subsection{Synthesis of silver doped $\mathrm{ZrO}_{2}\left(\mathrm{ZrO}_{2}-\mathrm{Ag}\right)$}

$3.5 \mathrm{~g}$ of $\mathrm{AgNO}_{3}$ was broken up in $10.5 \mathrm{~mL}$ of deionized water (Solution $\mathrm{C}$ ). The $\mathrm{C}$ was at that point poured dropwise to A beneath enthusiastically blending in dim, the 
blended solution D was ceaselessly blended till the gel was shaped. The gel was at that point dried at $374 \mathrm{~K}$ for $3 \cdot 1 / 2 \mathrm{~h}$, calcined at $674 \mathrm{~K}$ and after that ground to get the $\mathrm{ZrO}_{2}$ Ag nanoparticles.

\subsection{Synthesis of $\mathrm{ZrO}_{2}$-Ag-G}

To begin with, $0.333 \mathrm{~g}$ of graphite oxide (GO) was scattered into $250 \mathrm{~mL}$ of water and ultra-sonicated for $35 \mathrm{~min}$. Sonicated graphene oxide exchanged to arrangement D. At that point $31.5 \mathrm{~mL}$ of $1 \mathrm{M}$ sodium hydroxide included into the sonicated forerunner blend dropwise for ideal $\mathrm{pH}$. At that point, it blended for $2 \mathrm{~h}$ at $374 \mathrm{~K}$. The color of antecedent blend turned into coffee color, demonstrates the effectively combined of $G$ with $\mathrm{Ag}$ combined $\mathrm{ZrO}_{2}$ arrangement $\mathrm{E}$.

\subsection{Synthesis of $\mathrm{ZrO}_{2}-\mathrm{Ag}-\mathrm{G}-\mathrm{SiO}_{2}$}

For the synthesis of final nanocomposites, $1.1 \mathrm{~g}$ of triblock copolymer Pluronic F127 was included to an arrangement having $15 \mathrm{ml}$ of deionized water and $61 \mathrm{ml}$ of $2 \mathrm{M}$ $\mathrm{HCl}$ at $313 \mathrm{~K}$ with mixing up to the copolymer was totally broken down. At that point, $3.20 \mathrm{ml}$ of tetraethyl orthosilicate (TEOS) was included and blended at $314 \mathrm{~K}$ for $12 \cdot 1 / 2$ h. The arrangement was moved to a fixed holder and warmed to $374 \mathrm{~K}$ within the stove for $20 \mathrm{~h}$. The coming about white accelerate was sifted, washed with water and ethanol, and dried at $338 \mathrm{~K}$ overnight. At long last, the copolymer was evacuated by calcination in discuss at $824 K$ for $3 \cdot 1 / 2 \mathrm{~h}$. The solution $\mathrm{E}$ was drop-by-drop included to a container containing $0.3 \mathrm{~g}$ of the silica powder and this mixture blended with $374 \mathrm{~K}$ for $24 \mathrm{~h}$ and ultrasonicates for $1_{1 / 2} \mathrm{~h}$ and sifted the powder, washed with $1.5 \mathrm{~mL}$ of methanol, and dried at $338 \mathrm{~K}$ overnight. Calcined at $974 \mathrm{~K}$ at a surined of $283 \mathrm{~K} / \mathrm{min}$ and held at $974 \mathrm{~K}$ for 5 h. Dark color items were found. (Scheme 1. a)

\subsection{Preparation of ZAGS electrode}

ZAGS coated film was prepared using a routine doctor-blade strategy [38]. For the altered doctor-blade strategy, a thick ZS (synthesized $\left.\mathrm{ZrO}_{2}\right), \mathrm{ZA}\left(\mathrm{ZrO}_{2}-\mathrm{Ag}\right), \mathrm{ZAG}$ $\left(\mathrm{ZrO}_{2}-\mathrm{Ag}-\mathrm{GO}\right), \mathrm{ZAGS}\left(\mathrm{ZrO}_{2}-\mathrm{Ag}-\mathrm{GO}-\mathrm{SiO}_{2}\right)$ glue was prepared as takes after: To begin with, synthesized fabric powder $(1.1 \mathrm{~g})$ was mixed with ethylcellulose and acetone (1.5 $\mathrm{ml}$ ) in a mortar for $15 \mathrm{~min}$. After that, the prepared glues were coated on FTO glass to create a film, after that dried within the open state for 35 min. One drop greasing up oil 
was put onto the film surface and stabilized beneath $374 \mathrm{~K}$ in the dry oven for $25 \mathrm{~min}$ to decrease breaks.

\subsection{Characterization of the materials}

The phase structure and purity of as-synthesized products were examined by $\mathrm{X}$ ray diffraction (XRD, Rigaku, Japan) with $\mathrm{Cu}-\mathrm{K} \alpha$ radiation $\left(\lambda=1.5406^{\circ} \mathrm{A}\right)$ at $40 \mathrm{kV}, 30$ $m A$ over $2 \theta$ range of 20-70. Morphologies were studied utilizing scanning electron microscopy (SEM) and EDS analysis by utilizing an SEM (JSM-76710F, JEOL, Tokyo, Japan), a transmission electron microscopy (TEM) (JEM-4010, JEOL, Tokyo, Japan), and a high-resolution TEM (HRTEM) (JSM-76710F, JEOL, Tokyo, Japan) operated at $300 k V$ accelerating voltage. X-ray photoelectron spectroscopy (XPS), Diffuse Reflectance Spectroscopy (DRS, SolidSpec-3700, Japan), and Raman spectroscopy (RAMAN, LabRAM HR-800, Japan) analyses were performed by utilizing WI Tec. alpha 300 series. Porous characterization of ZAG and ZAGS structures were performed by a full analysis of $\mathrm{N}_{2}$ adsorption/desorption tests (BELSORP-max, BEL Japan Inc.). (PG201, Potentiostat, Galvanostat, Volta lab ${ }^{\mathrm{TM}}$, Radiometer, Denmark).

\subsection{Electrochemical measurements}

Cyclic voltammetry $(\mathrm{CV})$ and estimations were performed beneath a threeelectrode electrochemical set up to check the current and voltage profiles, where ZS, ZA, $\mathrm{ZAG}$, ZAGS was utilized as working cathode whereas platinum and $\mathrm{Ag} / \mathrm{AgCl}$ terminal was chosen as counter and reference anodes, individually. Electrochemical properties in commercial urine utilized with the measured $\mathrm{pH}$ 6.0, 6.7, and 6.5, individually. As electrolytes, $0.1 M \mathrm{NaOH}, 0.1 M \mathrm{KOH}$ and Buffer watery arrangement were utilized. The restrain of discovery of the analyte was calculated concurring to the taking after condition (Eq. 1): [39-41]

$$
L O D=3 S D / N
$$

where $S D$ is the standard deviation of the analyte concentration calculated from the current reaction of progressive including of glucose into the electrolyte; $N$ is the slant of the calibration bend which demonstrates the affectability of the anode with a signal-tonoise proportion of 3 . For all ponders, glucose concentration from to 2 molar proportion was went with by progressive increments of $0.8 \mathrm{mmol} / \mathrm{L}$ glucose into $5 \mathrm{~mL}$ testing urine arrangement. Moreover, $\mathrm{CV}$ tests were performed from -0.3 to $+0.2 \mathrm{~V}$ versus $\mathrm{Ag} / \mathrm{AgCl}$ at 
a filter rate of $50 \mathrm{mV} \mathrm{s}^{-1}$. Moreover, Starch, Vitamin C, Lactose were added as interferents within the urine test. All estimations were carried out by voltammetry (PG201, Potentiostat, Galvanostat, Volta lab TM, Radiometer, Denmark).

\section{Results and discussion}

\subsection{Characterization of the ZAGS sample}

The mesoporous semiconductors were anchored on graphene nanosheet since this mesoporous conductive arrangement encourages electron transport among nanostructure and electrolytes, hence making this an alluring stage for the design of biosensors. Fig. 1 illustrates the crystalline characteristic properties of ZS, ZA, ZAG and ZAGS samples affirmed by the X-ray diffraction (XRD) technique. The synthesized $\mathrm{ZrO}_{2}$ was indexed at $24.8^{\circ}$, grid plane (110). All diffraction peaks were well-indexed (JCPDS 37-1484). After adjustment with $\mathrm{Ag}, \mathrm{SiO}_{2}$ the $\mathrm{ZrO}_{2}-\mathrm{Ag}-\mathrm{G}-\mathrm{SiO}_{2}$ range appeared all diffraction peaks along the extra cpeaks comparing to (JCPDS 65-2871) and (JCPDS 39-1425), separately, affirming the immaculate crystalline nature of the samples.

Morphology of ZS, ZA, ZAG, and ZAGS was examined by Scanning electron microscopy (SEM). Fig. 2 demonstrates SEM pictures with low and high amplifications. Synthesized ZS in Fig. 2 (a) clearly appeared the permeable structure. Fig. 2 (d) showed that the ZAG combined with mesoporous $\mathrm{SiO}_{2}$. These figures showed that ZAGS were consistently disseminated. Such flake-like nanostructured geometry leads to a unpleasant surface of the cathode which can expectedly lead to upgrade of the anode execution on account of its high surface region, superior surface-to-volume proportion, and presentation of more electro-catalytically dynamic locales on ZAGS. The elemental state of the ZAGS nanoparticles was further more analyzed through EDS.

As shown in Fig. 3, composition of ZAGS was presented to confirm the coexistence of $\mathrm{Zr}, \mathrm{C}, \mathrm{Ag}$, and $\mathrm{Si}$ with the evaluated composition within the gravimetric rate of $29 \%$ $\mathrm{Zr}, 35 \% \mathrm{C}, 12 \% \mathrm{Ag}$ and $5 \% \mathrm{Si}$. Nanostructured morphology of the electrodeposited film was checked by a profoundly amplified TEM picture of ZAGS in Fig. 4. As appeared within the HRTEM picture, the grid space of $0.28 \mathrm{~nm}$ was given out to the interplanar of the (111) plane of the ZS sample and another cross section space of 0.26 $\mathrm{nm}$ was arranged to the interplanar of the (022) plane of the ZAGS sample. Raman 
spectroscopy was also performed to characterize the $\mathrm{G}$ band showing in the composite.

As shown in Fig. 5 (a), the $\mathrm{G}$ band of as-synthesized sample appeared two peaks located at 1331 and $1573 \mathrm{~cm}^{-1}$ comparing to the (D band) and the C-C bond extending recurrence ( $\mathrm{G}$ band), individually. For the most part, the concentrated proportion of the D- and $\mathrm{G}$ bands (ID/IG) is utilized to evaluate the degree of disorder and the normal estimate of $\mathrm{sp}^{2}$ spaces. In this fact, the value of ID/IG was calculated to be 0.94. Fig. 5 (b) presents the $\mathrm{N}_{2}$ adsorption-desorption isotherms of ZAG and ZAGS samples. ZAG and ZAGS samples display ordinary type IV isotherm, illustrating that materials had mesopores. Isotherms of samples display a $\mathrm{H}_{2}$ type hysteresis circle at a relative pressure $\left(P / P_{0}\right)$ between 0.6 and 0.9 , appearing that these materials have extensively and consistently conveyed mesopores. In addition, the hysteresis circles continuously move to higher relative pressure $\left(P / P_{0}\right)$ from ZAG to ZAGS, proposing that these mesopores were extending with the counting mesoporous $\mathrm{SiO}_{2}$. A mesopore size as large as $5.67 \mathrm{~nm}$ finds out the ZAG sample. When combining through mesoporous $\mathrm{SiO}_{2}$ it proceeds to extend up to $8.96 \mathrm{~nm}$ as well as Wagered surface range too expanded from 8.66 to $9.17 \mathrm{~m}^{2} \mathrm{~g}$, individually (Table 1). The electrochemical properties of nanocomposites were correlated with the BJH and BET analysis results. From BET analysis, the total pore volume and mean pore diameter of sensor active material is reduced due to the oxidizing agent treatment. According to the summary results of BET and BJH, the surface area and total pore mass (mesopore and micropore) of the graphite increased with $\mathrm{SiO}_{2}$. The micro-sized pore state and high surface area are the main parameters that are valuable for framing ion-transport tunnels in electro-chemical reactions.

The resultant absorbance of UV-DRS is depicted in Fig. 5 (c). Optical band gap of the ZC, ZS, ZA, ZAG, ZAGS, can be determined by the (eq. 2): [43]

$$
(\alpha h v)^{1 / 2}=A(h v-E g)
$$

Where ' $\alpha$ ' was the molar assimilation coefficient calculated as $\alpha=(1-R)^{2} / 2 R$, $h v$ is the occurrence light recurrence, ' $A$ ' is the proportionality consistent, and ' $E_{g}$ ' is the band gap energy of the fabric. Table 1 outlines the information form $(\alpha h v)^{1 / 2}$ as a work of photon vitality. Band gaps diminish from $4.79 \mathrm{eV}$ for the $\mathrm{ZC}$ to $3.25 \mathrm{eV}$ for ZS. To examine the band gap energy, the value of $\mathrm{Ag}$ doped ZA diminish to $3.11 \mathrm{eV}$. Continuously after combining with graphene, the band gap energy of the ZAG turned to $2.61 \mathrm{eV}$. The band 
gap energy values alter astoundingly to $2.00 \mathrm{eV}$ within the ZAGS after combining through mesoporous $\mathrm{SiO}_{2}$. Valence band (VB) and conduction band (CB) possibilities of all the tests were calculated based on the taking after conditions [43]

$$
\begin{aligned}
& E_{\mathrm{CB}}=X-E \mathrm{e}-\frac{1}{2} E_{\mathrm{g}} \\
& E_{\mathrm{VB}}=E_{\mathrm{CB}}+E_{\mathrm{g}}
\end{aligned}
$$

Here, $E_{\mathrm{VB}}$ and $E_{\mathrm{CB}}$ are valence and conduction band edge possibilities, individually. c is the electronegativity of the semiconductor, $E_{\mathrm{e}}$ is the vitality of free electrons on the hydrogen scale and $E_{\mathrm{g}}$ is the band gap energy vitality of the semiconductor. In the attractive field assurance, one-level compelling mass estimation (EMA) is utilized for a basic non-degenerate vitality band. Bloch electrons in a vitality band are treated as free electrons with the free electron mass $\mathrm{m} 0$ supplanted by the viable mass $\mathrm{m}^{*}$. The Schrodinger condition for the work of the conduction electron in electric and attractive areas can be appeared with the taking after condition [42].

$$
B=\frac{\mu 0 I}{2 \pi r}
$$

Fig. 5 (d) shows the attractive field bends of the ZAGS sample measured at surrounding temperature. The immersion magnetization (MS), which is decided by the plot of $\mathrm{M}$ versus $1 / \mathrm{H}$ utilizing information at moo attractive areas, is watched to be $0.0036 .5 \mathrm{emu}^{-}$${ }^{1}$ to $0.0046 .5 \mathrm{emu}^{-1}$.

For characterization of actual surface chemical compositions of $\mathrm{ZrO}_{2}-\mathrm{Ag}-\mathrm{G}-\mathrm{SiO}_{2}$, XPS examination was performed. The outputs are uncovered in Fig. 6 (a). The total range of $\mathrm{ZrO}_{2}-\mathrm{Ag}-\mathrm{G}-\mathrm{SiO}_{2}$ appears the characteristic $\mathrm{Si}, \mathrm{Zr}, \mathrm{C}, \mathrm{Ag}$ and $\mathrm{O}$ peaks ascribed to the successful modification. The comparing high-resolution spectra regard to C1s flag 284.5 $\mathrm{eV}$ as a reference official vitality in Fig. 6 (b) ascribed to $\mathrm{C}-\mathrm{C}$, bonds of graphene. As existing in Fig. 6 (c), Si2p peak found at $102.8 \mathrm{eV}$. These peaks found at $184.08 \mathrm{eV}$ compare to Zr3d in Fig. 6 (d). Other than, the interaction of the carbonyl, and hydroxyl groups was moreover confirmed in O1s existing in Fig. 5 (e) with the official vitality at $531.6 \mathrm{eV}$ comparing to C-O bonds. At last, the peaks at 367.0 and $373.1 \mathrm{eV}$ showed in Fig. 6 (f) compare to Ag3d. The general output for XPS deeply suggested that all surface chemical compositions of ZAGS found on the surface of the as-prepared nanocomposite.

3.2 Electrocatalytic activity of the ZAGS electrode towards glucose sensing 
The electrochemical tests for working anodes named ZS, ZA, ZAG, ZAGS were performed in a three-electrode cell framework with Pt wire as counter electode and $\mathrm{Ag} / \mathrm{AgCl}$ as a reference electrode inside the potential extend of -0.3 to $+0.3 \mathrm{~V}$. Fig. 7 (a) presents the $\mathrm{CV}$ profile of electrochemical reaction in $10.5 \mathrm{~mL}$ of commercial urine and diverse electrolytes without glucose. There was small oxidation as shown in Fig. 7 (a) without the glucose. In addition, ZS, ZA, ZAG and ZAGS anodes appeared a welldefined oxidation at the potential of $+0.2 \mathrm{~V}$. By including of $0.05 \mathrm{mmol} / \mathrm{L}$ of glucose, a reaction was noticed with the ZS instead of ZA, ZAG and ZAGS electrodes within the permitted concentration of glucose, due to the high band gap vitality of $\mathrm{ZrO}_{2}$. After combining with Ag nanoparticle and graphene, the band gap vitality diminished (Fig. 5 (c)), due to ZA, ZAG and ZAGS have great conductivity. Furthermore, in our sensor system, the electrode of $\mathrm{Ag}-\mathrm{G}-\mathrm{SiO}_{2}$ supported with $\mathrm{ZrO}_{2}$ has quickly transporting electrons from the electrochemical response, due to their great conductive property. ZAGS anode shows a significant increment in anodic current amounts $\left(4.0 \times 10^{-3} \mathrm{mAcm}^{-2}\right)$ as appeared in Fig. 7 (b). For changing electrolytes such as $0.1 M$ phosphate buffer, $\mathrm{NaOH}, \mathrm{KOH}$, noteworthy and quick current reaction amounts $\left(9.0 \times 10^{-3} \mathrm{mAcm}^{-2}\right)$ were observed at the ZAGS cathode with the expansion of $0.55 \mathrm{mmol} / \mathrm{L}$ glucose as displayed in Fig. 7 (c). The obtained result clearly suggests the high oxidation compares to the electrooxidation of glucose at the ZAGS anode [44].

In the modeling to illustrate the explanatory parameters (for illustration affectability, straight extend, discovery restrain and reaction time), the amperometric reaction of the ZAGS electrode was performed at a fixed voltage of $+0.2 \mathrm{~V}$ (versus $\mathrm{Ag} / \mathrm{AgCl}$ ) in $0.1 M$ PBS by stepwise including of glucose at diverse concentration. A well-defined and quick reaction to the ZAGS electrode showed. Fig. 7 (d) shows the current reaction which was assessed to be as high as $5.0 \times 10^{-3} \mathrm{~mA} \mathrm{~cm}^{-2}$ at lower glucose concentration $(0.05$ to $0.35 \mathrm{mmol} / \mathrm{L})$. By including glucose, the current reaction rapidly come to a steady-state and accomplishes $\sim 98 \%$ of reaction inside $1 \mathrm{~s}$. The reaction current was straightly expanded with expanding glucose concentration, ZAGS electrode shows high affectability within the direct extend $(0.05$ to $0.35 \mathrm{mmol} / \mathrm{L})$. By the way, the upgraded detecting performance of non-enzymatic glucose sensor is attributed to the coordinate development of mesoporous ZAGS film on FTO substrate, which offers a 
high surface area by $\mathrm{ZrO}_{2}$ attachment, coming about in quick electron exchange by the electrochemical reactions of glucose oxidation happening between electrolyte and active material. In this modeling, we have utilized the self-assembly strategy to manufacture non-enzymatic ZAGS glucose-sensing electrode which accounted for controllable nanostructures with incredible reproducibility and cost-effective preparation for steady glucose detecting device.

\subsection{Selection of electrolytes towards ZAGS electrode}

Detecting of glucose by ZAGS test cell with distinctive electrolytes (PBS, $\mathrm{NaOH}$; $\mathrm{KOH})$ and distinctive concentrations was examined broad encompassing conditions. Glucose oxidation with these electrolytes was measured in $0.1 M \mathrm{NaOH}$, phosphate buffer and $\mathrm{KOH}$ by consequent expansion of $0.55 \mathrm{mmol} / \mathrm{L}$ of glucose at customary interims and tested the current reactions after each infusion. Fig. 8 (a) appears that when $0.55 \mathrm{mmol} / \mathrm{L}$ of glucose in various concentrations of electrolytes brought about in nearly the most excellent current thickness towards the phosphate buffer electrolytes. The current state of the ZAGS electrode incredibly depends on glucose concentration and electrolyte $\mathrm{pH}$ (i.e. the sum of $\mathrm{OH}^{-}$), since $\mathrm{OH}^{-}$require to neutralize the protons created from dehydrogenation reaction of the reactants. Consequently, "distant better; a much better; higher; stronger; an improved" a stronger result is confirmed towards phosphate buffer for the ZAGS electrode.

As portrayed over, the affectability and straight run of glucose detecting can be found by plotted current thickness against glucose concentrations as appeared in Fig. 7 (d). In $0.05 \mathrm{mmol} / \mathrm{L}$ glucose concentration, the sensor reaction had an affectability of $4.0 \times 10^{-3}$ $m A \mathrm{~cm}^{-2}$ and $0.35 \mathrm{mmol} / \mathrm{L}$ glucose concentrations. The sensor reaction had an affectability of $5.0 \times 10^{-3} \mathrm{mAcm}^{-2}$. It is that the reaction running is corresponding to the concentration running. So, after check this ratio we effortlessly reach to this choice that is able to degree a diabetic urine test with this sensor for subjective and quantitative investigation.

\subsection{Anti-interference ability of the ZAGS sensor}


Anti-interference capacity of non-enzymatic based glucose detecting devices may be a major challenge, which seems influence the electrode's detecting performance. To check the selectivity of ZAGS electrode with the some kinds of interferometer species (such as Vitamin $\mathrm{C}$, Starch, Lactose, Fructose, $\mathrm{NaCl}, \mathrm{KCl}$ and Urea), the amperometric reaction of the detecting anode was checked by including of $0.91 \mathrm{mmol} / \mathrm{L}$ glucose and each over specified interferometer species was in same concentration within the $0.1 \mathrm{M}$ PBS arrangement at $+0.2 V$ (versus $\mathrm{Ag} / \mathrm{AgCl}$ ), as shown in Fig. 8 (b). The expansion of $0.91 \mathrm{mmol} / \mathrm{L}$ glucose leads to a quick current reaction, although interferometer species expansion shown insignificant current reactions. As appeared within the histogram of each interferometer species expansion and current reaction is appeared here, which confirmed the insignificant current reactions compared to $0.91 \mathrm{mmol} / \mathrm{L}$ glucose. These output about recommend the appropriateness of the ZAGS electrode for the detecting of glucose in actual tests. It suggests that the ZAGS electrode was specific towards glucose without being influenced by interferer. This upgraded detecting performance essentially credited to an great interaction among the nanostructure and anode with the high surface area for catalytic destinations, encouraging a reasonable way for electron transport from electrochemical movement. The outputs obtained from the proposed strategy were compared with other strategies for the location of glucose. The ZAGS electrodes can be imagined as a promising plan for non-enzymatic glucose estimation in actual clinical tests which may pick up significant benefits for diverse biomolecules detecting.

\subsection{Glucose sensing mechanism}

The electrocatalytic properties of ZAGS active sensing material were inspected towards applications including the physiological $\mathrm{pH}$, and the concentration of glucose. Considering that glucose can be oxidized to gluconolactone (Fig. 8) at an impartial pH by means of a two-electron electrochemical response [50]. Be that as it may, a great sensing reaction was observed with the ZAGS sensor in the presence of glucose. This could be ascribed to the great electrocatalytic nature of $\mathrm{ZrO}_{2}$, which intercedes the heterogeneous chemical oxidation or lessening of the glucose, whereas the change over $\mathrm{ZrO}_{2}$ can be persistently and at the same time recouped by electrochemical oxidation or diminishment due to their high surface area to volume proportion [51]. Also, in our sensor system, the $\mathrm{Ag}-\mathrm{G}-\mathrm{SiO}_{2}$ works as a supporting matrix with the $\mathrm{ZrO}_{2}$, which shows quickly electron 
transporting effect with the electrochemical response due to their great conductive property. Moreover, the less thick morphology of the $\mathrm{Ag}-\mathrm{G}-\mathrm{SiO}_{2}$ gives superior penetrability of the detecting lattice to the arrangement. The conceivable electrochemical responses included in glucose oxidation through the $\mathrm{Zr}^{4+} / \mathrm{Zr}^{3+}$ centers of $\mathrm{ZrO}_{2}$ are given underneath [51]:

$$
\begin{aligned}
& \mathrm{Zr}^{4+}+\text { Glucose }\left(\mathrm{C}_{6} \mathrm{H}_{12} \mathrm{O}_{6}\right) \rightarrow \mathrm{Zr}^{3+}+\text { Gluconolactone }\left(\mathrm{C}_{6} \mathrm{H}_{10} \mathrm{O}_{6}\right)+\mathrm{H}_{2} \mathrm{O} \\
& \text { Gluconolactone }\left(\mathrm{C}_{6} \mathrm{H}_{10} \mathrm{O}_{6}\right)+\mathrm{H}_{2} \mathrm{O} \rightarrow 2 \mathrm{H}^{+}+\text {Gluconate }\left(\mathrm{C}_{6} \mathrm{H}_{12} \mathrm{O}_{7}\right) \\
& \qquad 2 \mathrm{Zr}^{3+} \rightarrow 2 \mathrm{Zr}^{4+}+2 \mathrm{e}^{-}
\end{aligned}
$$

In this manner, electrooxidation of glucose on ZAGS for the nonenzymatic location of glucose at physiological $\mathrm{pH}$ was examined.

\section{Conclusions}

In this study, we suggests a basic approach for creating ZAGS utilizing the feasible self-assembly strategy, creating a catalyst-coated and binder-free composite anode. The ZAGS as sensing active material showed a uniform and profoundly mesoporous arrange of the catalytic film. Moreover, various dynamic results for the ZAGS sample with improved conductivity of graphene oxide made the advanced electrocatalytic performance of this electrode towards glucose oxidation. The ultra-high affectability (9.0 $\times 10^{-3} \mathrm{~mA} \mathrm{~cm}^{-2}$ ) with a small potential variation as it were $0.2 \mathrm{~V}$ versus $\mathrm{Ag} / \mathrm{AgCl}$, wide direct extend $(0.05 \sim 0.35 \mathrm{mmol} / \mathrm{L})$, small detecting restrain $(0.05 \mathrm{mmol} / \mathrm{L})$, with noteworthy subjective and quantitative investigation, selectivity and solidness make the ZAGS as promising electrode to serve as a non-enzymatic glucose sensor. Based on the output, ZAGS given a great affectability in commercial urine examples, which is acceptable as biosensor to have a tall plausibility for commonsense use. 


\section{DECLARATIONS}

-Ethical Approval

We had kept the Ethical fields in all of terms. In this research process, we did not used any illegal and inhibited human test, drug and instrument.

\section{-Consent to Participate}

We confirm that the manuscript has been read and approved by all named authors and that there are no other persons who satisfied the criteria for authorship but are not listed.

\section{-Consent to Publish}

We further confirm that the order of authors listed in the manuscript has been approved for this publication by all of us.

\section{-Authors Contributions}

We understand that the Corresponding Author is the sole contact for the Editorial process $\mathrm{He}$ is responsible for communicating with the other authors about experimental progress, submissions of revisions and final approval of proofs. We confirm that we have provided a current, correct email address which is accessible by the Corresponding Author and which has been configured to accept email from.

\section{-Funding}

For the publication, there has been no significant financial support for this work that could have influenced its outcome.

\section{-Competing Interests}

We wish to confirm that there are no known conflicts of interest associated with this publication

\section{-Availability of data and materials}

We the undersigned declare that this manuscript is original with new data and synthesized novel materials, has not been published before and is not currently being considered for publication elsewhere. 


\section{References}

[1] Hui N and Wang J, (2017) Electrodeposited honeycomb-like cobalt nanostructures on graphene oxide doped polypyrrole nanocomposite for high performance enzymeless glucose sensing. Journal of Electroanalytical Chemistry 798:9-16.

[2] Pletcher D, (1984) Electrocatalysis: present and future. Journal of applied electrochemistry 14(4):403-415.

[3] Toghill KE and Compton RG, (2010) Electrochemical non-enzymatic glucose sensors: a perspective and an evaluation. Int. J. Electrochem. Sci 5(9):1246-1301.

[4] Fu S, Fan G, Yang L and Li F, (2015) Non-enzymatic glucose sensor based on Au nanoparticles decorated ternary $\mathrm{Ni}-\mathrm{Al}$ layered double hydroxide/single-walled carbon nanotubes/graphene nanocomposite. Electrochimica acta 152:146-154.

[5] Sun KG and Hur SH, (2015) Highly sensitive non-enzymatic glucose sensor based on Pt nanoparticle decorated graphene oxide hydrogel. Sensors and Actuators B: Chemical 210:618-623.

[6] Wu GH, Song XH, Wu YF, Che, XM, Luo F and Chen X, (2013) Non-enzymatic electrochemical glucose sensor based on platinum nanoflowers supported on graphene oxide. Talanta 105:379-385.

[7] Hou, L Zhao, H Bi, S Xu Y and Lu Y, (2017) Ultrasensitive and highly selective sandpaper-supported copper framework for non-enzymatic glucose sensor. Electrochimica Acta 248:281-291. 
[8] Liu X, Yang W, Chen L and Jia, (2017) Three-dimensional copper foam supported $\mathrm{CuO}$ nanowire arrays: an efficient non-enzymatic glucose sensor. Electrochimica Acta 235:519-526.

[9] Zhong Y, Shi T, Liu Z, Cheng S, Huang Y, Tao X, Liao G and Tang Z, (2016) Ultrasensitive non-enzymatic glucose sensors based on different copper oxide nanostructures by in-situ growth. Sensors and Actuators B: Chemical 236:326-333.

[10] Wang Q, Wang Q, Li M, Szunerits S and Boukherroub R, (2015) Preparation of reduced graphene oxide/Cu nanoparticle composites through electrophoretic deposition: application for nonenzymatic glucose sensing. RSC Advances 5(21):15861-15869.

[11] Fatema K N, Biswas MRUD, Bang SH, Cho KY and Oh WC, (2020) Electroanalytical characteristic of a novel biosensor designed with graphenepolymer-based quaternary and mesoporous nanomaterials. Bulletin of Materials Science 43(1).

[12] Fatema KN, Sagadevan S, Liu Y, Cho KY, Jung CH and Oh WC, (2020) New design of mesoporous $\mathrm{SiO}_{2}$ combined $\mathrm{In}_{2} \mathrm{O}_{3}$-graphene semiconductor nanocomposite for highly effective and selective gas detection. Journal of Materials Science 55(27):13085-13101.

[13] Hai B. and Zou Y, (2015) Carbon cloth supported NiAl-layered double hydroxides for flexible application and highly sensitive electrochemical sensors. Sensors and Actuators B: Chemical 208:143-150. 
[14] Li X, Liu J, Ji X, Jiang J, Ding, R Hu, Y Hu A and Huang X, (2010) Ni/Al layered double hydroxide nanosheet film grown directly on Ti substrate and its application for a nonenzymatic glucose sensor. Sensors and Actuators B Chemical 147(1):241247.

[15] Shu Y, Yan Y, Chen J, Xu Q, Pang H and Hu X, (2017) Ni and NiO nanoparticles decorated metal-organic framework nanosheets: facile synthesis and highperformance nonenzymatic glucose detection in human serum. ACS applied materials \& interfaces 9(27):22342-22349.

[16] Farid MM, Goudini L, Piri F, Zamani A and Saadati F, (2016) Molecular imprinting method for fabricating novel glucose sensor: Polyvinyl acetate electrode reinforced by $\mathrm{MnO}_{2} / \mathrm{CuO}$ loaded on graphene oxide nanoparticles. Food chemistry 194:61-67.

[17] Yang S, Liu L, Wang G, Li G, Deng D and Qu L, (2015) One-pot synthesis of $\mathrm{Mn}_{3} \mathrm{O}_{4}$ nanoparticles decorated with nitrogen-doped reduced graphene oxide for sensitive nonenzymatic glucose sensing. Journal of Electroanalytical Chemistry $755: 15-21$.

[18] Balamurugan J, Thanh TD, Karthikeyan G, Kim NH and Lee JH, (2017) A novel hierarchical 3D N-Co-CNT@ NG nanocomposite electrode for non-enzymatic glucose and hydrogen peroxide sensing applications. Biosensors and Bioelectronics 89:970-977.

[19] Chung JS and Hur SH, (2016) A highly sensitive enzyme-free glucose sensor based on $\mathrm{Co}_{3} \mathrm{O}_{4}$ nanoflowers and $3 \mathrm{D}$ graphene oxide hydrogel fabricated via hydrothermal synthesis. Sensors and Actuators B: Chemical 223:76-82. 
[20] Cao X and Wang N, (2011) A novel non-enzymatic glucose sensor modified with $\mathrm{Fe}_{2} \mathrm{O}_{3}$ nanowire arrays. Analyst 136(20):4241-4246.

[21] Xia C and Ning W, (2010) A novel non-enzymatic electrochemical glucose sensor modified with $\mathrm{FeOOH}$ nanowire. Electrochemistry Communications 12(11):15811584.

[22] Liu JM, Hu Y, Yang YK, Liu H, Fang GZ, Lu X and Wang S, (2018) Emerging functional nanomaterials for the detection of food contaminants. Trends in Food Science \& Technology 71:94-106.

[23] Ambrosi A, Chua CK, Bonanni A and Pumera M, (2014) Electrochemistry of graphene and related materials. Chemical reviews 114(14):7150-7188.

[24] Viswanathan S, Narayanan TN, Aran K, Fink KD, Paredes J, Ajayan PM Filipek S, Miszta P, Tekin HC, Inci F and Demirci U, (2015) Graphene-protein field effect biosensors: glucose sensing. Materials Today 18(9):513-522.

[25] Liu J, Meng X, Hu Y, Geng D, Banis MN, Cai M, Li R. and Sun X, (2015) Controlled synthesis of zirconium oxide on graphene nanosheets by atomic layer deposition and its growth mechanism. Carbon 52:74-82.

[26] Gong J, Miao X, Wan H and Song D, (2012) Facile synthesis of zirconia nanoparticles-decorated graphene hybrid nanosheets for an enzymeless methyl parathion sensor. Sensors and Actuators B: Chemical 162(1):341-347. 
[27] Liao L, Bai J, Lin YC, Qu Y, Huang Y and Duan X. (2010) High Performance Top Gated Graphene-Nanoribbon Transistors Using Zirconium Oxide Nanowires as High Dielectric Constant Gate Dielectrics. Advanced Materials 22(17):1941-1945.

[28] Du D, Liu J, Zhang X, Cui X. and Lin Y, (2015) One-step electrochemical deposition of a graphene- $\mathrm{ZrO}_{2}$ nanocomposite: preparation, characterization and application for detection of organophosphorus agents. Journal of Materials Chemistry 21(22):8032-8037.

[29] Cho BH and Ko WB, (2013) Preparation of graphene- $\mathrm{ZrO}_{2}$ nanocomposites by heat treatment and photocatalytic degradation of organic dyes. Journal of nanoscience and nanotechnology 13(11):7625-7630.

[30] Cho B and Ko W, (2013) Preparation of $\mathrm{ZrO}_{2}-\mathrm{C}_{60}$ nanocomposites using heat treatment and photocatalytic degradation of organic dyes. Asian Journal of Chemistry 25(8):4577-4582.

[31] Lee YL, Kim S, Park C, Ihm J and Son YW, (2010) Controlling half-metallicity of graphene nanoribbons by using a ferroelectric polymer. ACS Nano 4(3):1345-1350.

[32] Sandeep S, Santhosh AS, Swamy NK, Suresh GS, Melo JS and Mallu P, (2016) Biosynthesis of silver nanoparticles using Convolvulus pluricaulis leaf extract and assessment of their catalytic, electrocatalytic and phenol remediation properties. Adv Mater Lett 7(5):383-389.

[33] Rosenholm JM, Meinander A, Peuhu E, Niemi R, Eriksson JE, Sahlgren C and Lindén M, (2009) Targeting of porous hybrid silica nanoparticles to cancer cells. ACS Nano 3(1):197-206. 
[34] Trewyn BG, Slowing II, Giri S, Chen HT and Lin VSY, (2007) Synthesis and functionalization of a mesoporous silica nanoparticle based on the sol-gel process and applications in controlled release. Accounts of Chemical Research 40(9):846853.

[35] Amin BG, Masud J and Nath M, (2019) A non-enzymatic glucose sensor based on a $\mathrm{CoNi}_{2} \mathrm{Se}_{4} / \mathrm{rGO}$ nanocomposite with ultrahigh sensitivity at low working potential. Journal of Materials Chemistry B 7(14):2338-2348.

[36] Saraf M, Natarajan K and Mobin SM, (2016) Non-enzymatic amperometric sensing of glucose by employing sucrose templated microspheres of copper oxide $(\mathrm{CuO})$. Dalton Transactions 45(13):5833-5840.

[37] Biswas MRUD and Oh WC, (2019) Comparative study on gas sensing by a Schottky diode electrode prepared with graphene-semiconductor-polymer nanocomposites. RSC advances 9(20):11484-11492.

[38] Kwon GH, Kim TW, Lee HI, Cho WC, Kim HY, (2019) Synthesis of $\mathrm{ZrO}_{2}$ Nanorods and Their Application as Membrane Materials. J. Korean Ceram. Soc. 56(6):541-548.

[39] Deng Z, Long H, Wei Q, Yu Z, Zhou B, Wang Y, Zhang L, Li S, Ma L, Xie Y and Min J, (2017) High-performance non-enzymatic glucose sensor based on nickelmicrocrystalline graphite-boron doped diamond complex electrode. Sensors and Actuators B: Chemical 242:825-834. 
[40] Zhou Y, Zheng H, Chen X, Zhang L, Wang K, Guo J, Huang Z, Zhang B, Huang W, Jin K and Tonghai D, (2009) The Schistosoma japonicum genome reveals features of host-parasite interplay. Nature 460(7253):345.

[41] Zhan B, Liu C, Chen H, Shi H, Wang L, Chen P, Huang W and Dong X, (2014) Free-standing electrochemical electrode based on $\mathrm{Ni}(\mathrm{OH})$ 2/3D graphene foam for nonenzymatic glucose detection. Nanoscale 6(13):7424-7429.

[42] Zawadzki W, (1973) Semiconductor electrons in electric and magnetic fields. Surface Science 37:218-243.

[43] Yang Z, Hu K, Meng X, Tao Q, Dong J, Liu B, Lu Q, Zhang H, Sundqvist B, Zhu P and Yao M, (2018) Tuning the band gap and the nitrogen content in carbon nitride materials by high temperature treatment at high pressure. Carbon 130:170-177.

[44] Ahmad R, Tripathy N, Ahn MS, Bhat KS, Mahmoudi T, Wang Y, Yoo JY, Kwon DW, Yang HY and Hahn YB, (2017) Highly efficient non-enzymatic glucose sensor based on $\mathrm{CuO}$ modified vertically-grown $\mathrm{ZnO}$ nanorods on electrode. Scientific reports 7(1):1-10.

[45] Sedighi A, Montazer M and Mazinani S, (2019) Synthesis of wearable and flexible $\mathrm{NiP}_{0.1}-\mathrm{SnO}_{\mathrm{x}} / \mathrm{PANI} / \mathrm{CuO} /$ cotton towards a non-enzymatic glucose sensor. Biosensors and Bioelectronics 135:192-199.

[46] Chen Y, Zhong Q, Wang Y, Yuan C, Qin X and Xu Y, (2019) Colorimetric detection of hydrogen peroxide and glucose by exploiting the peroxidase-like activity of papain. RSC advances 9(29):16566-16570. 
[47] Wang B, Ju P, Zhang D, Han X, Zheng L, Yin X and Sun C, (2016) Colorimetric detection of $\mathrm{H}_{2} \mathrm{O}_{2}$ using flower-like $\mathrm{Fe}_{2}\left(\mathrm{MoO}_{4}\right)_{3}$ microparticles as a peroxidase mimic. Microchimica Acta 183(11):3025-3033.

[48] Ma Q and Nakazato $\mathrm{K}$, (2014) Low-temperature fabrication of $\mathrm{ZnO}$ nanorods/ferrocenyl-alkanethiol bilayer electrode and its application for enzymatic glucose detection. Biosensors and Bioelectronics 51:362-365.

[49] Luo JJ, Pan SW, Yang JH, Chang TL, Lin PY, Wu CL, Liu WF, Huang XR, Koshevoy IO, Chou PT and Ho ML, (2018) Detecting Glucose Levels in Blood Plasma and Artificial Tear by Au (I) Complex on the Carbopol Polymer: A Microfluidic Paper-Based Method. Polymers 10(9):1001-1011.

[50] Tomanin PP, Cherepanov PV, Besford QA, Christofferson AJ, Amodio A, McConville CF, Yarovsky I, Caruso F and Cavalieri F, (2018) Cobalt phosphate nanostructures for non-enzymatic glucose sensing at physiological pH. ACS Applied Materials \& Interfaces 10(49):42786-42795.

[51] Ahmad R, Ahn MS and Hahn YB, (2017) Fabrication of a non-enzymatic glucose sensor field-effect transistor based on vertically-oriented $\mathrm{ZnO}$ nanorods modified with $\mathrm{Fe}_{2} \mathrm{O}_{3}$. Electrochemistry Communications 77:107-111. 

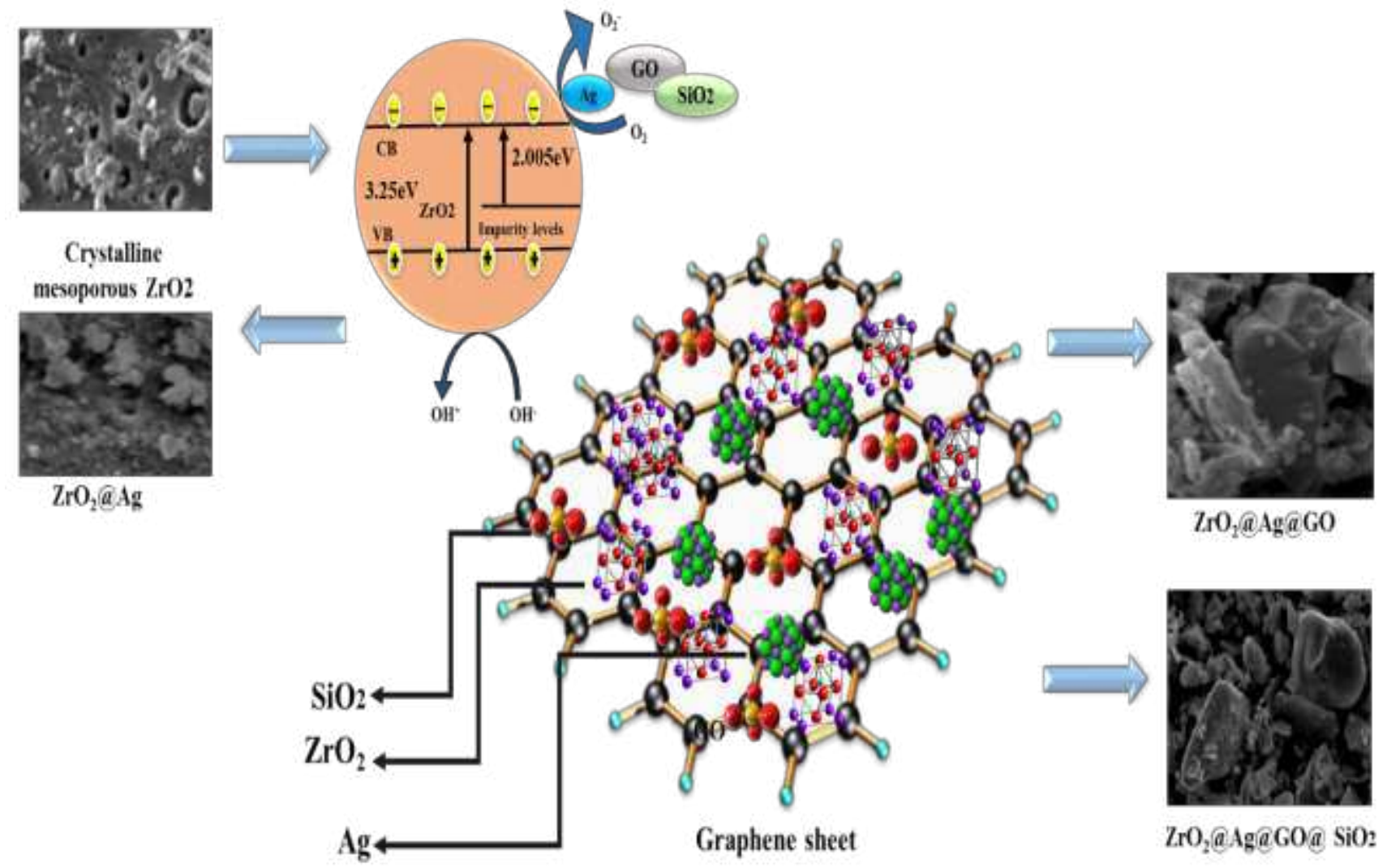

(a) 


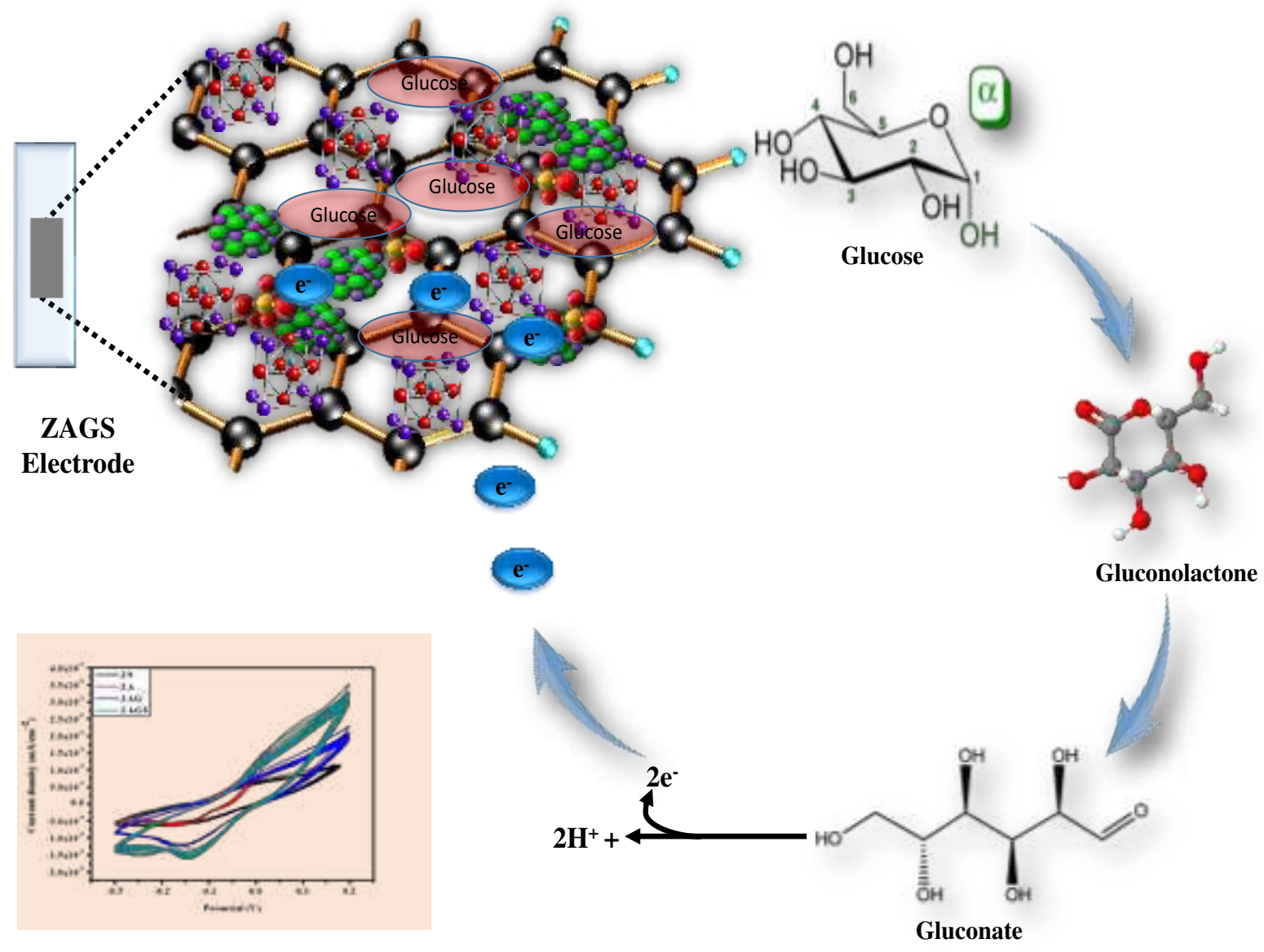

(b)

Scheme. 1. (a) Schematic diagram of the synthesis of the ZAGS sample (b) The glucosesensing mechanism of the ZAGS sample. 


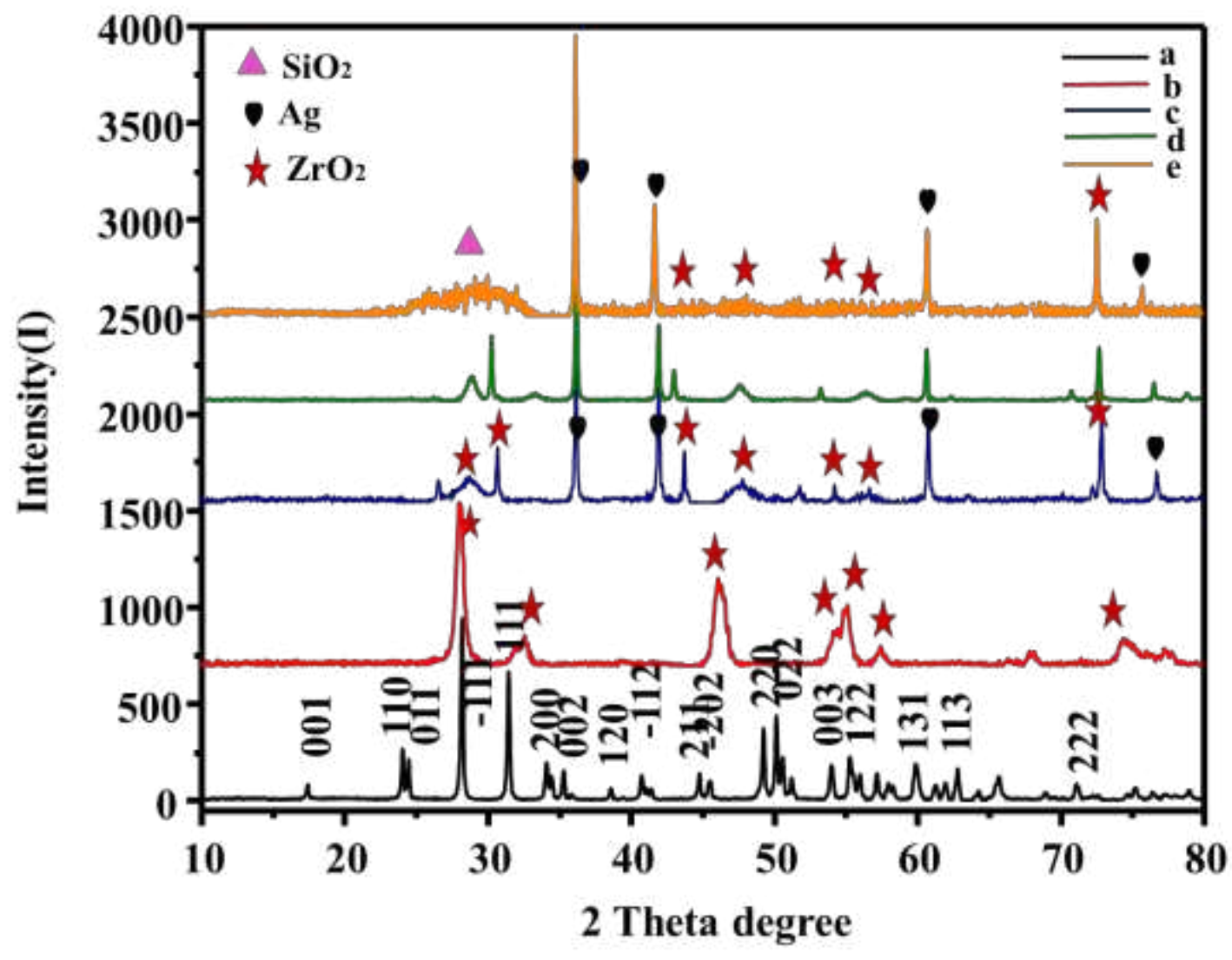

Fig.1. XRD patterns of ZC (a), ZS (b), ZA(c), ZAG (d) and ZAGS (e). 

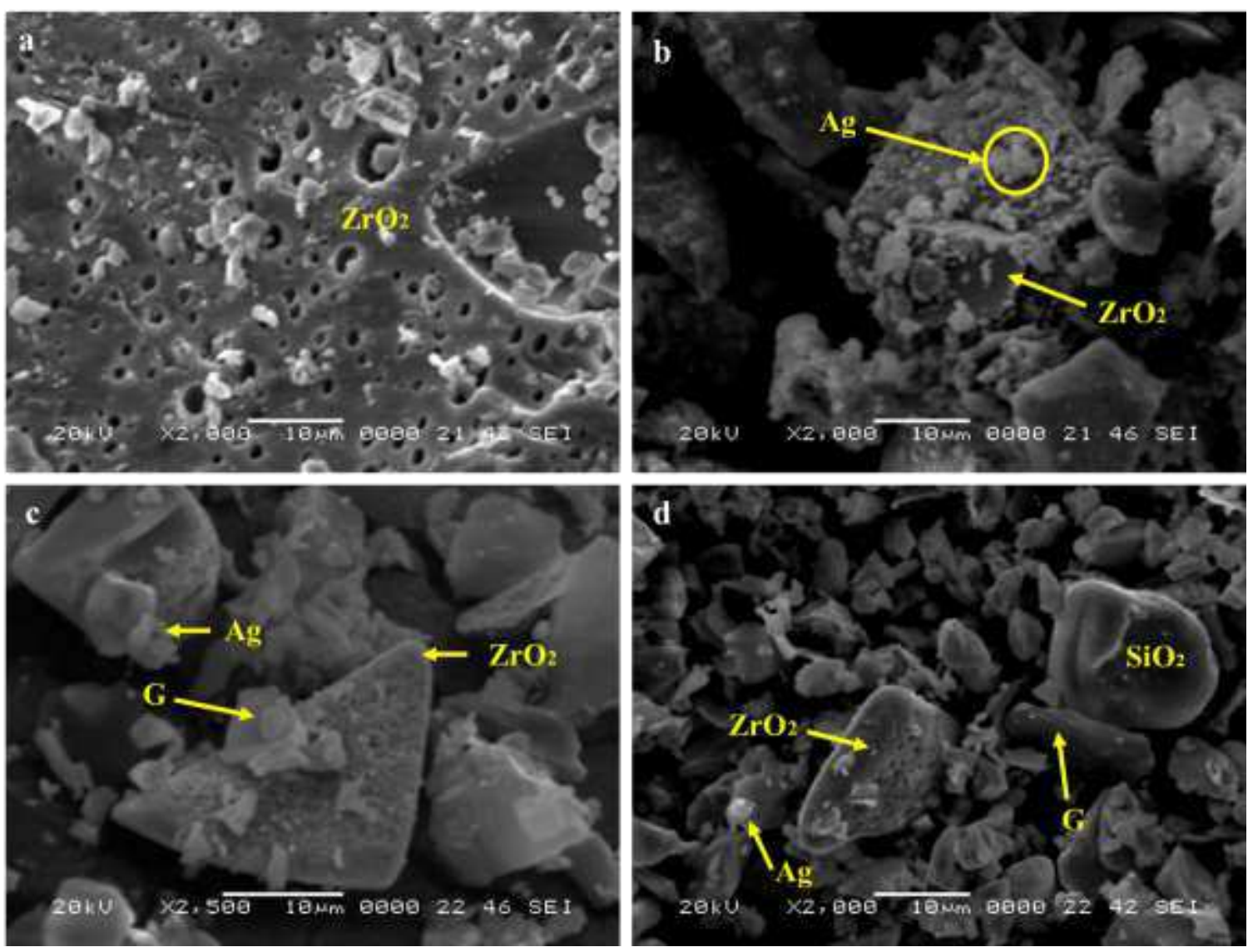

Fig.2. SEM images of ZS, ZA, ZAG and ZAGS. 


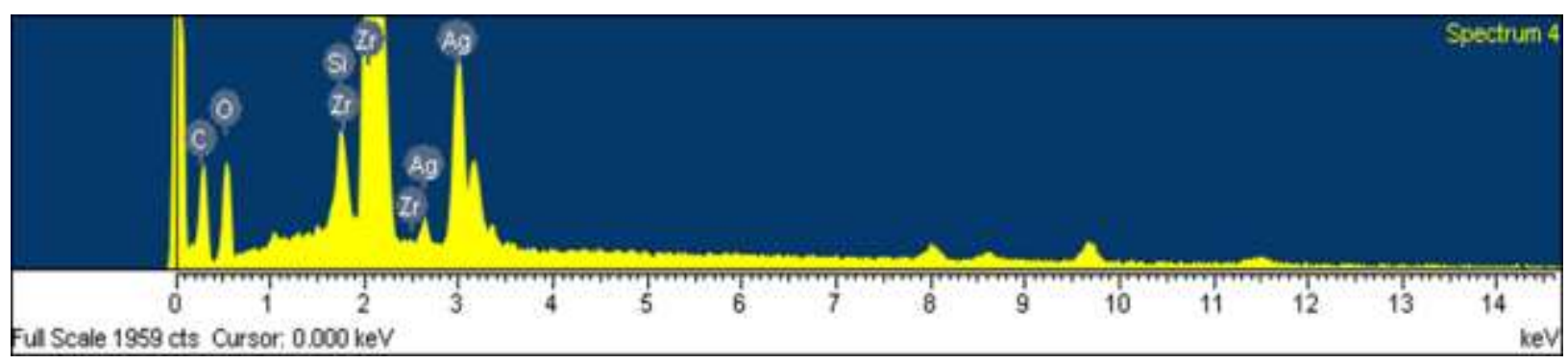

\section{Quantitative results}

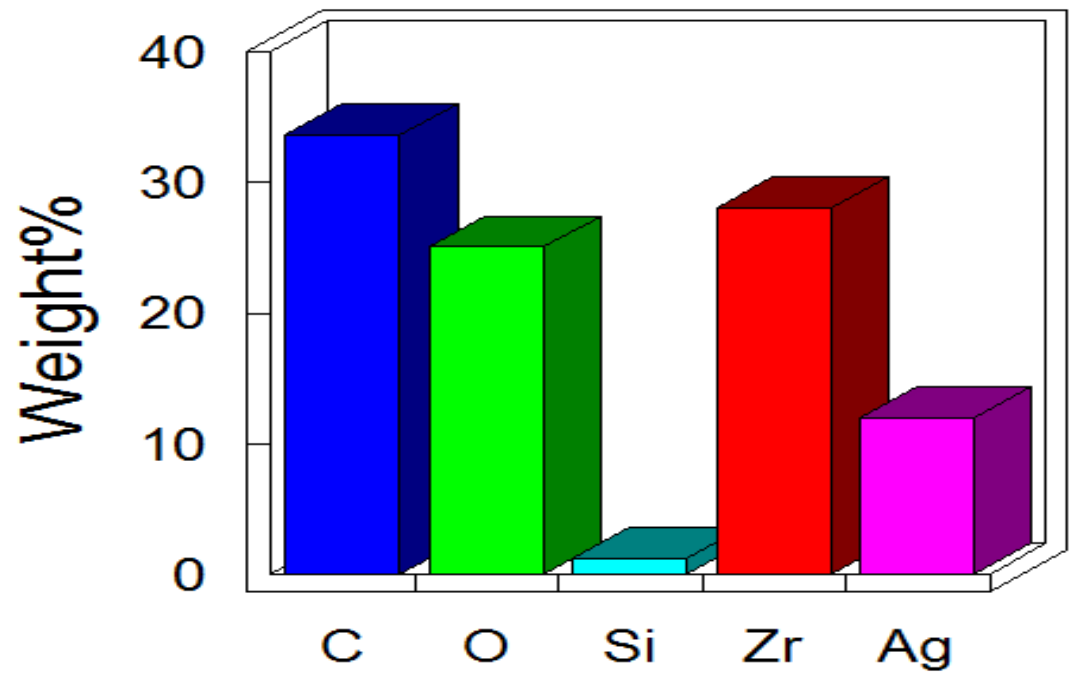

Fig.3. EDS of ZAGS Samples. 

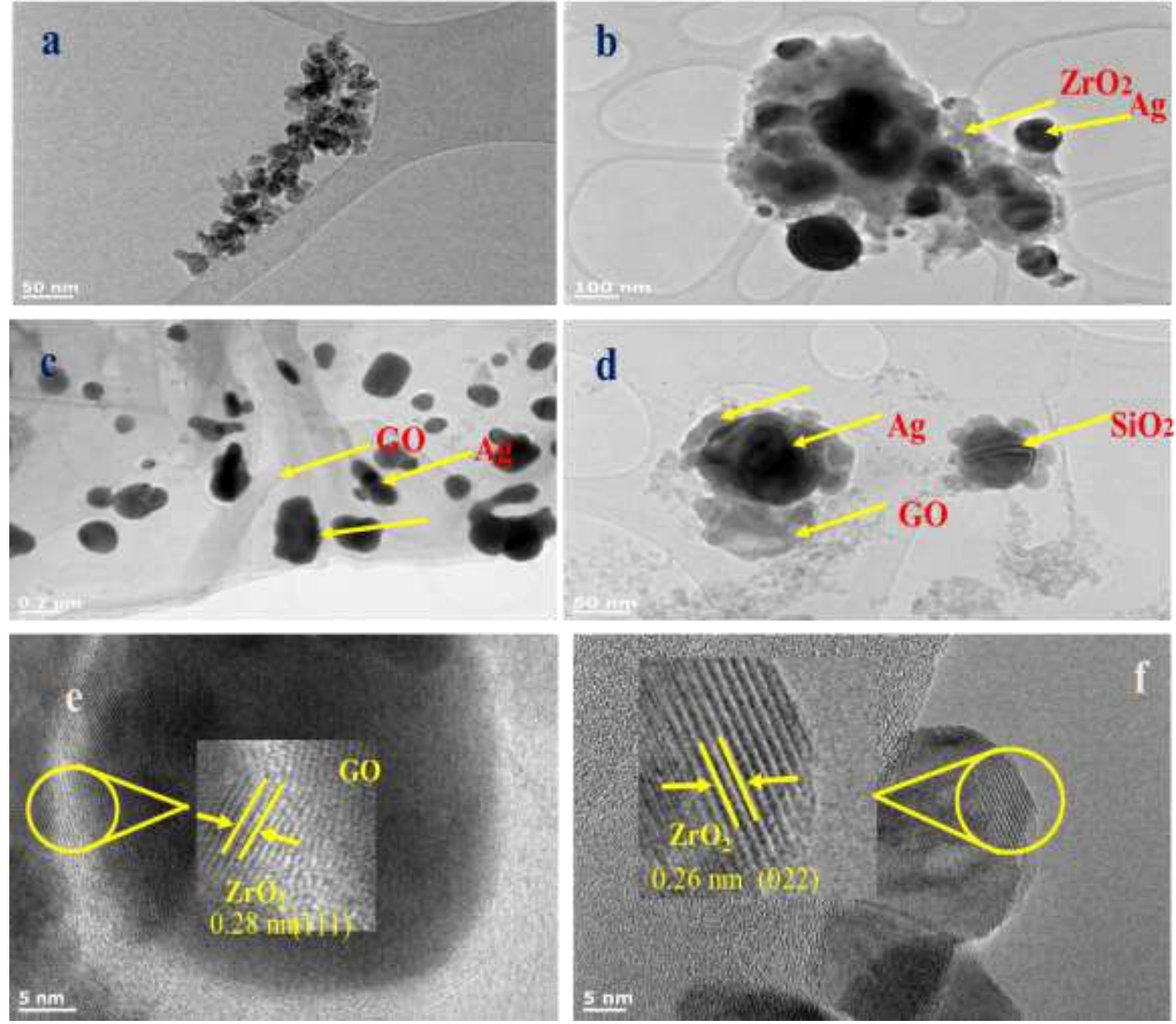

Fig.4. TEM Images of ZS (a) ZA (b); ZAG(c); ZAGS (d) and HRTEM Images of ZS (e) ZAGS (f). 


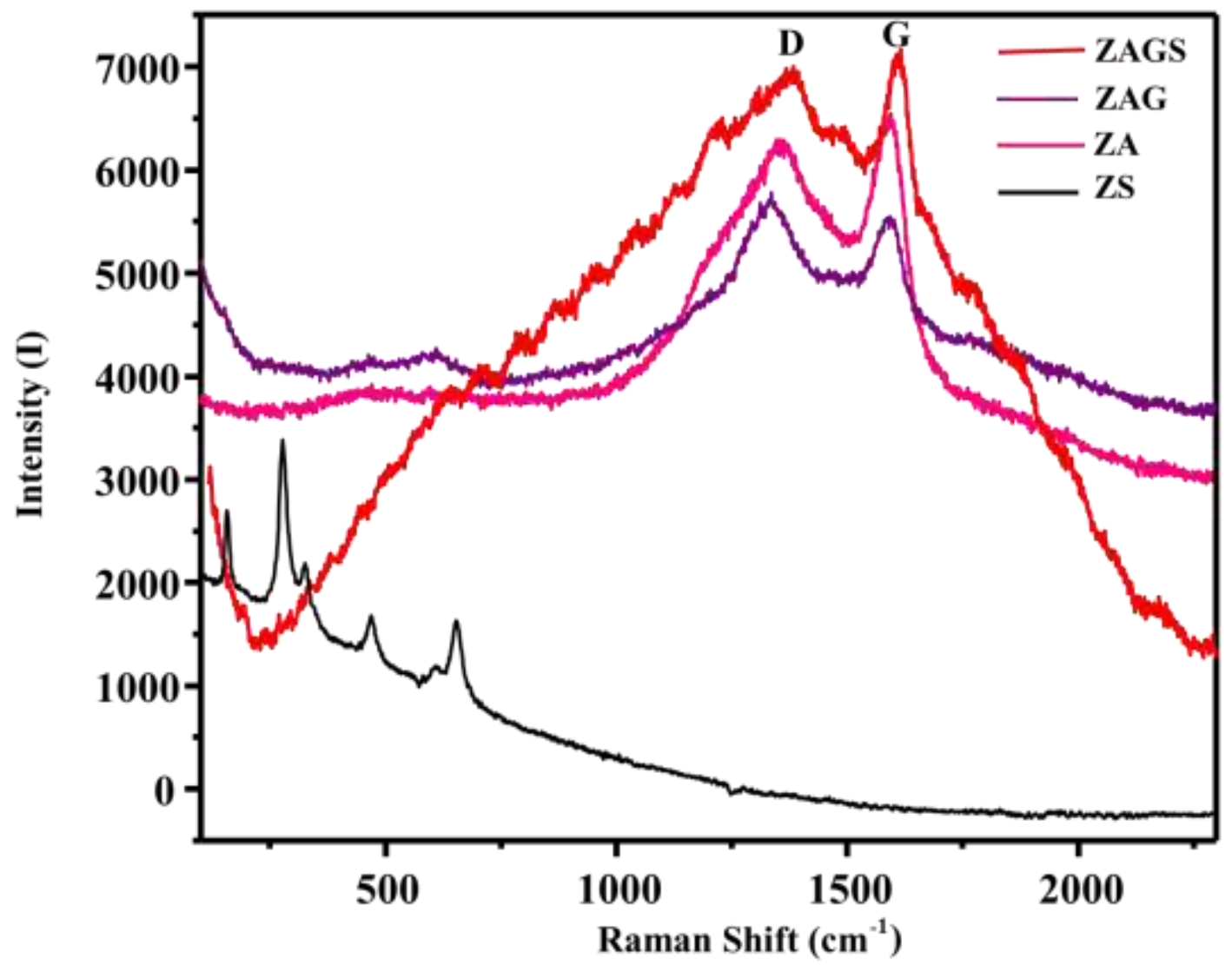

(a) 


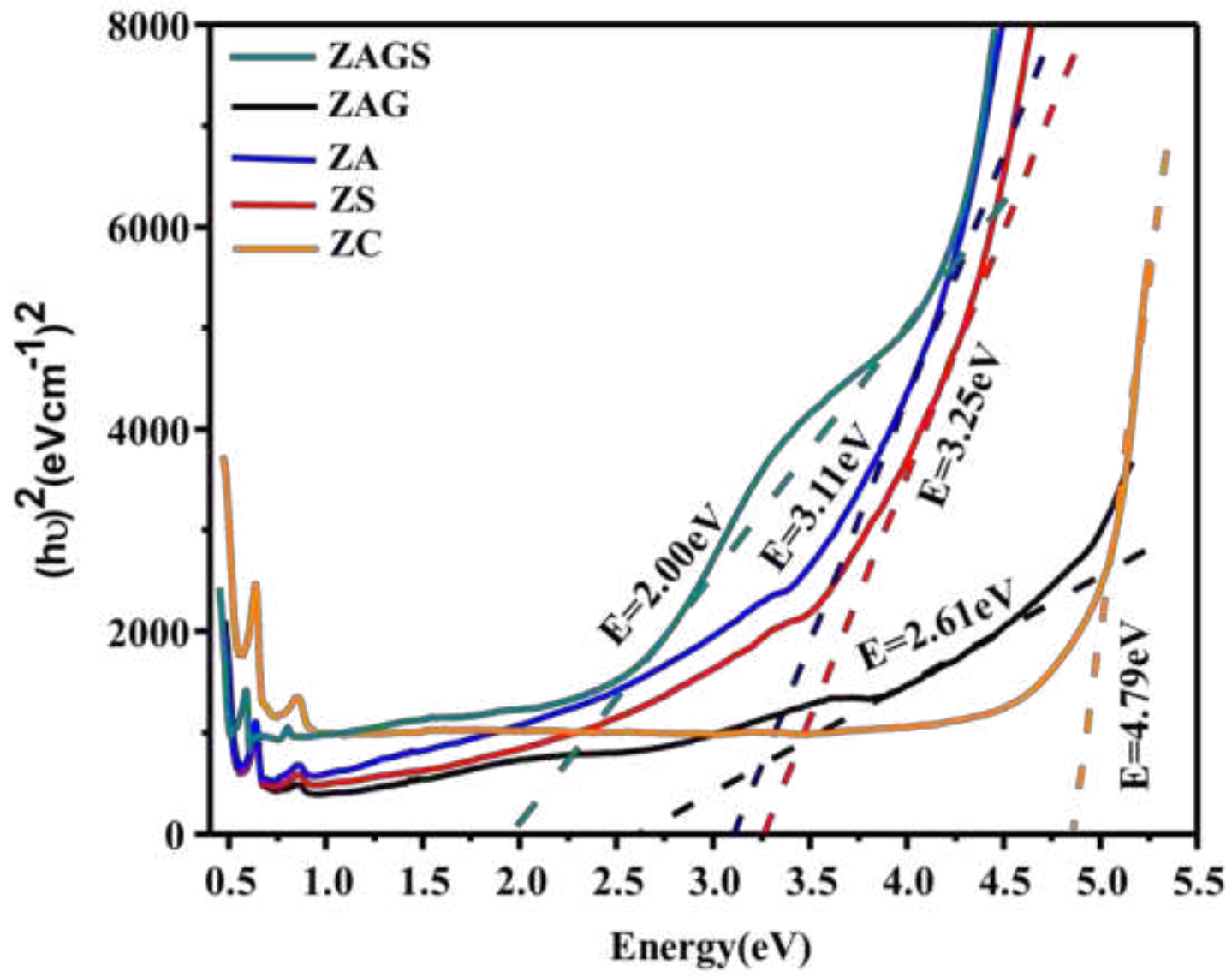

(b) 


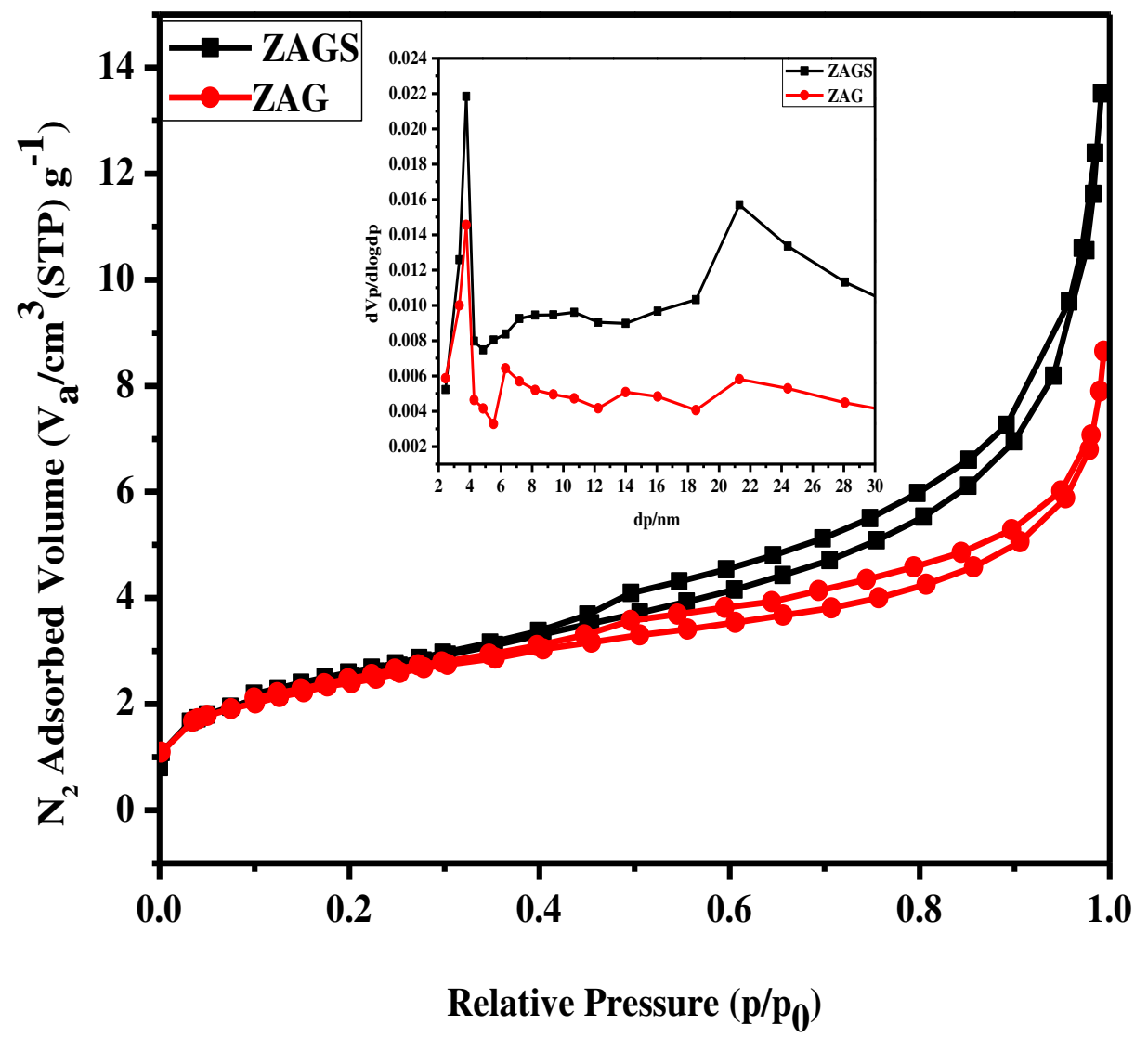

(c) 


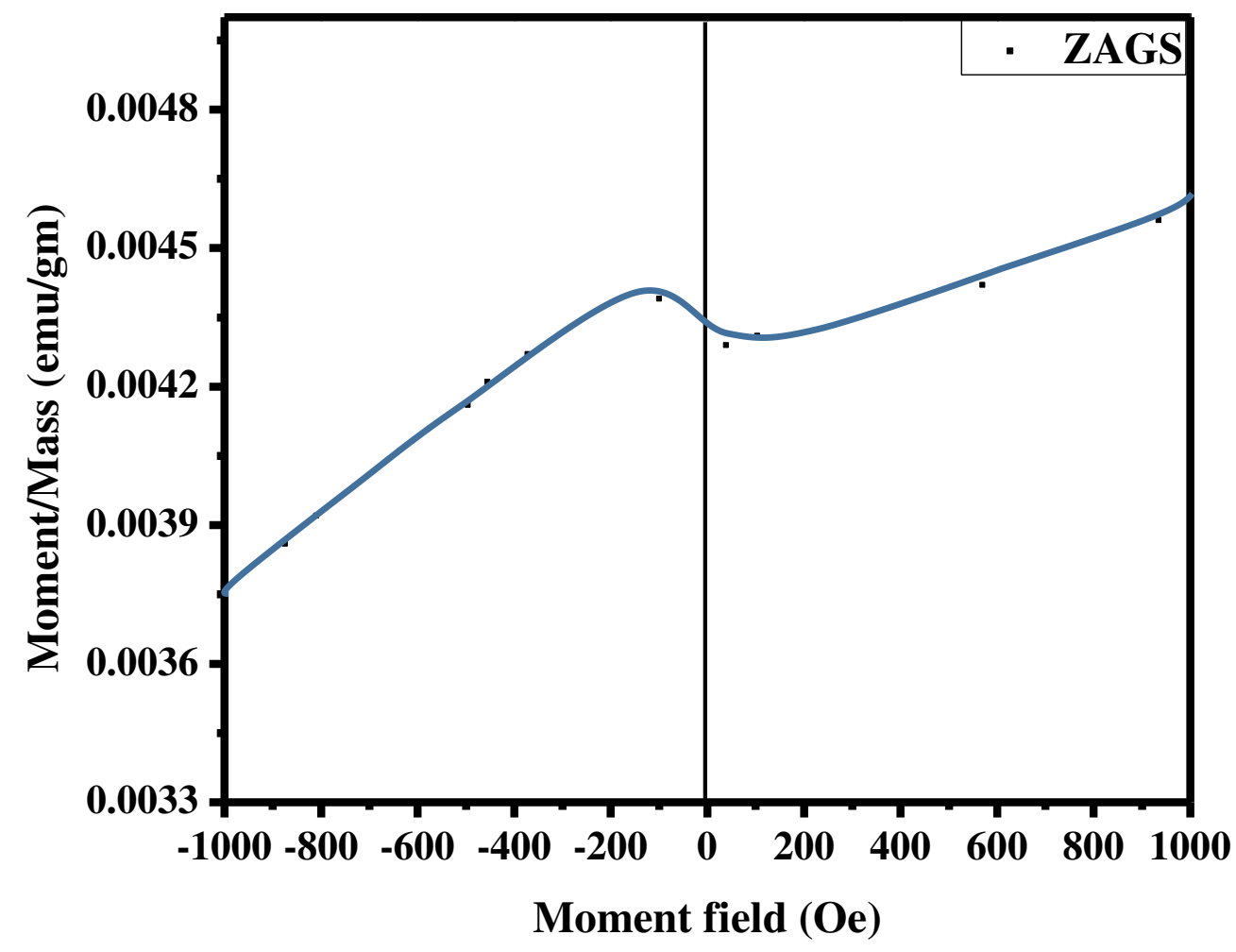

(d)

Fig. 5. (a) Raman spectra of ZS, ZA, ZAG and ZAGS sample, (b) Nitrogen adsorptiondesorption isotherms of ZAG, ZAGS; and the corresponding pore size distributions (inset), (c) DRS data of ZC, ZS, ZA, ZAG, ZAGS and (d) Magnetic field area of ZAGS. 


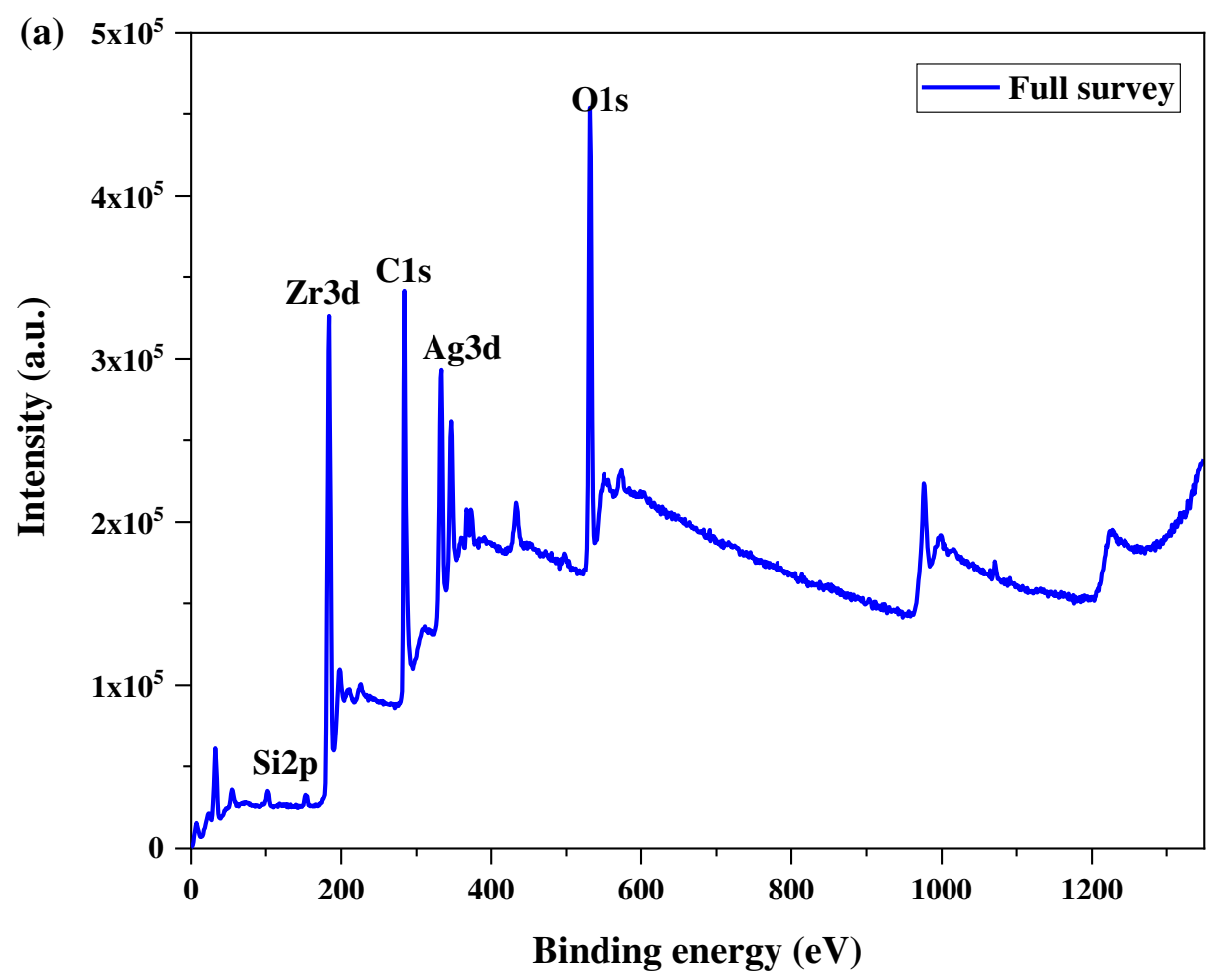



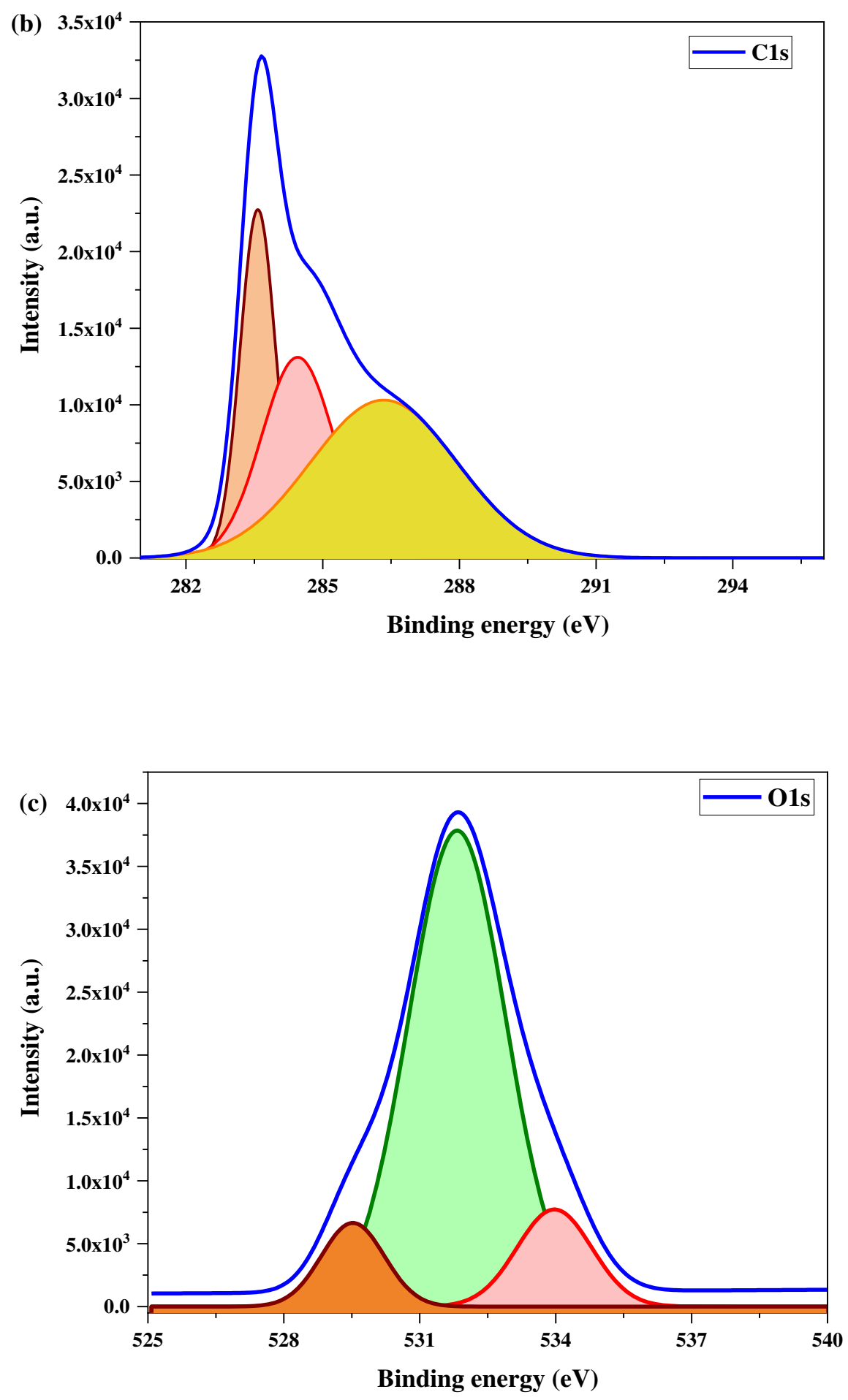

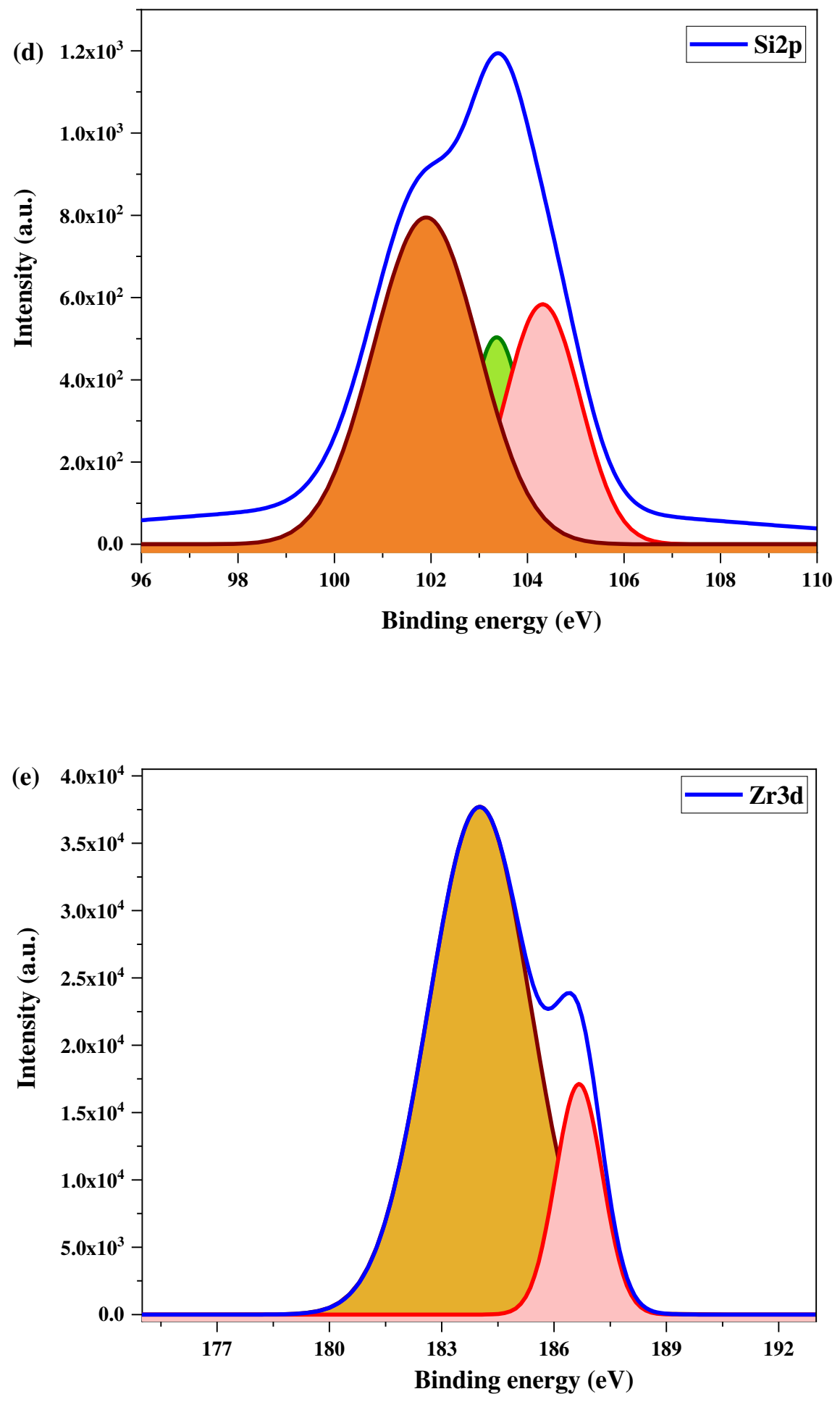


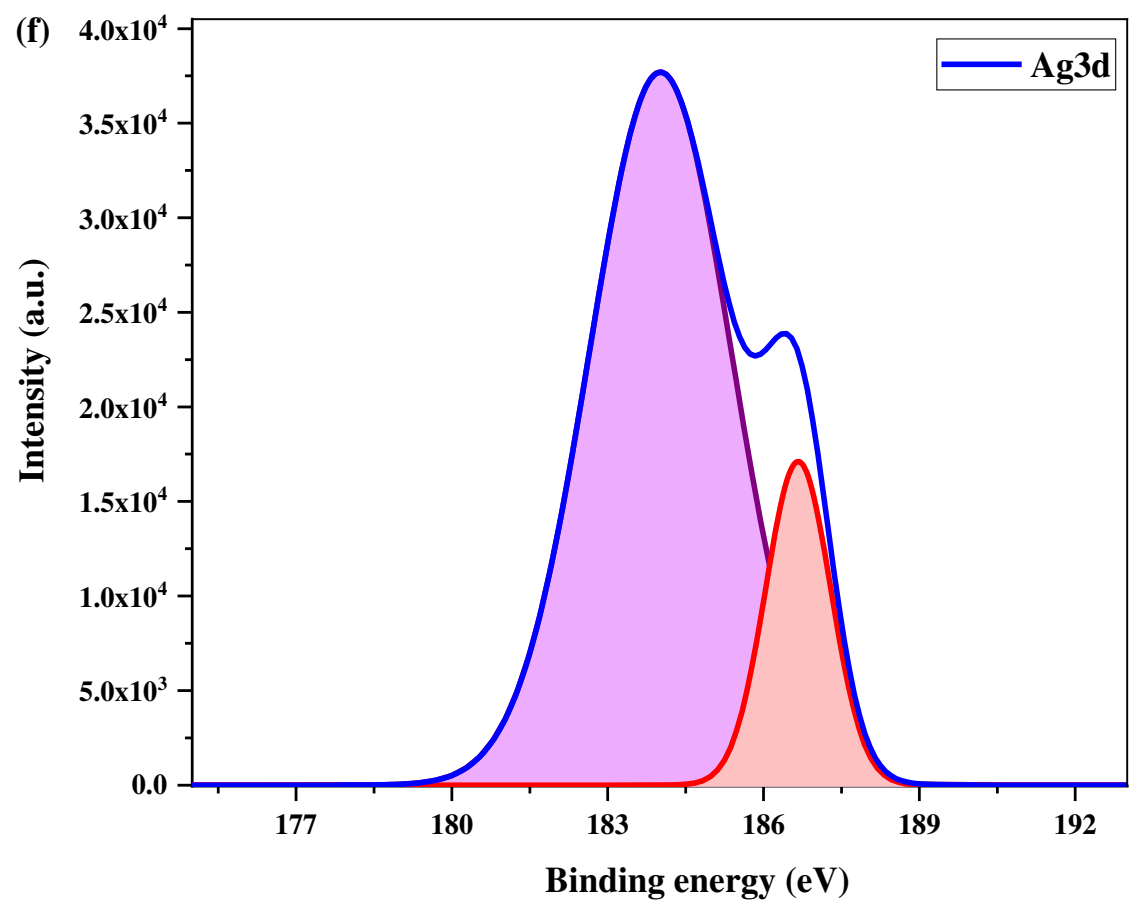

Fig. 6. XPS spectra of ZAGS (a) survey, C1s (b), Si2p (c), Zr3d (d), O1s (e) and Ag3d (f). 


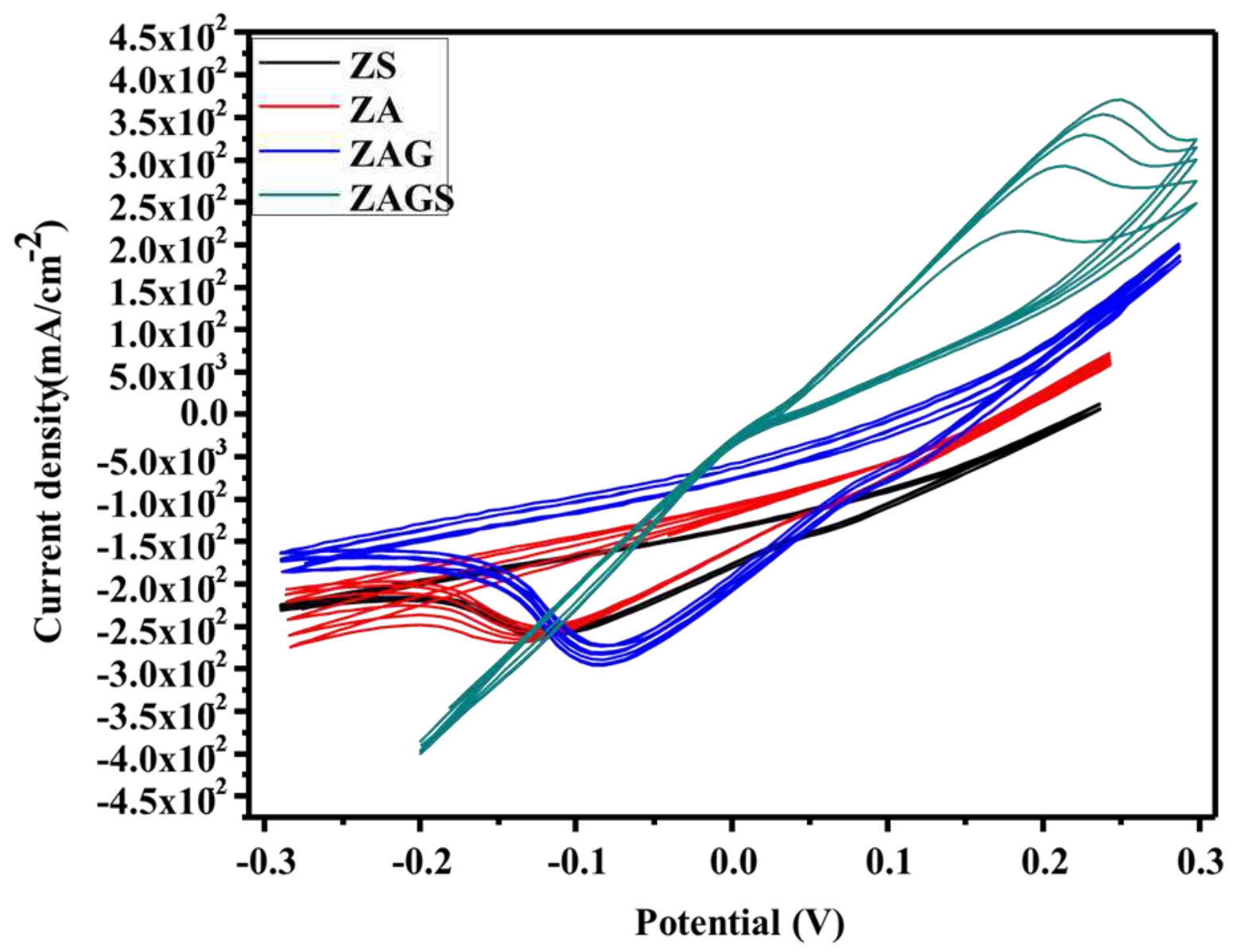

(a) 


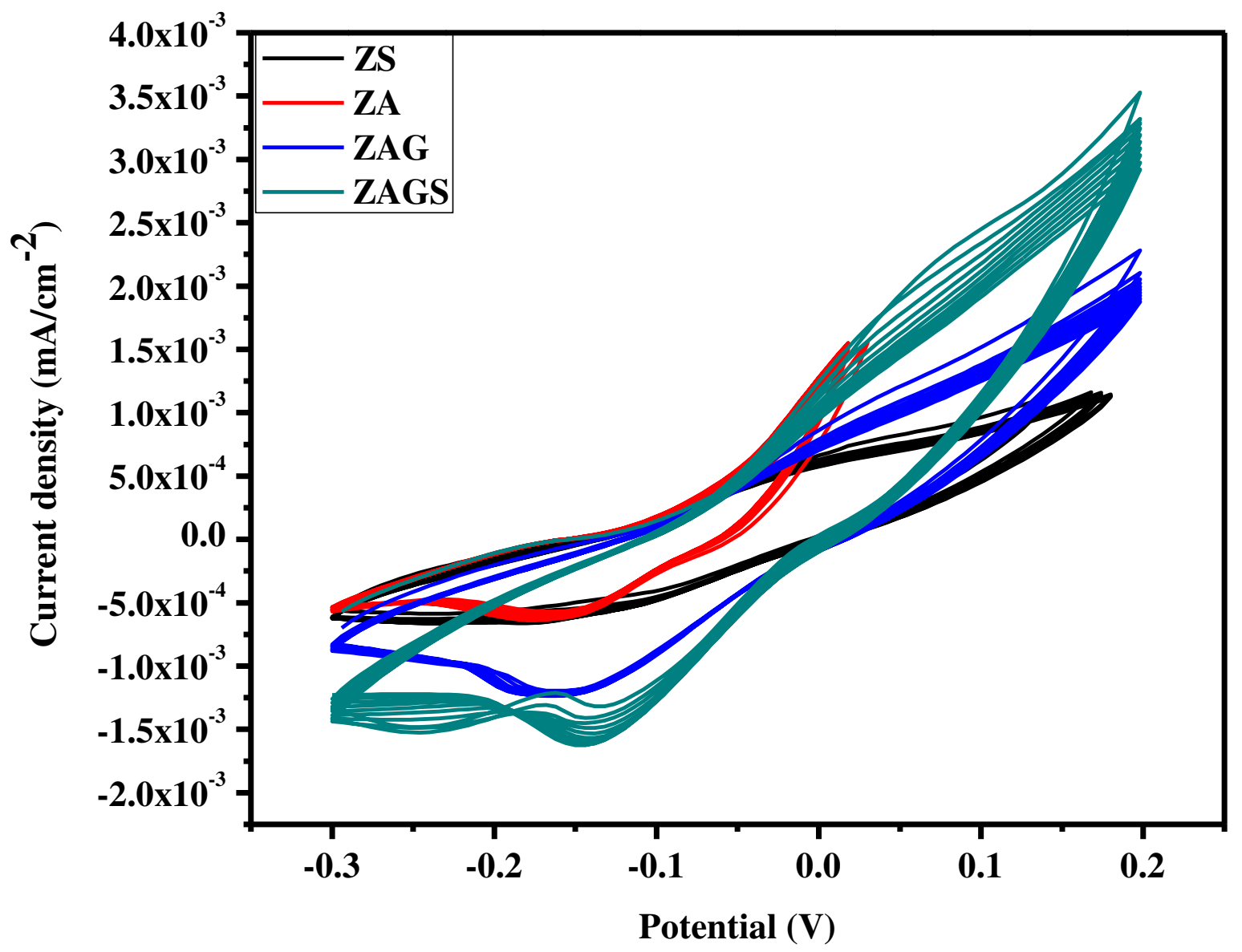

(b) 


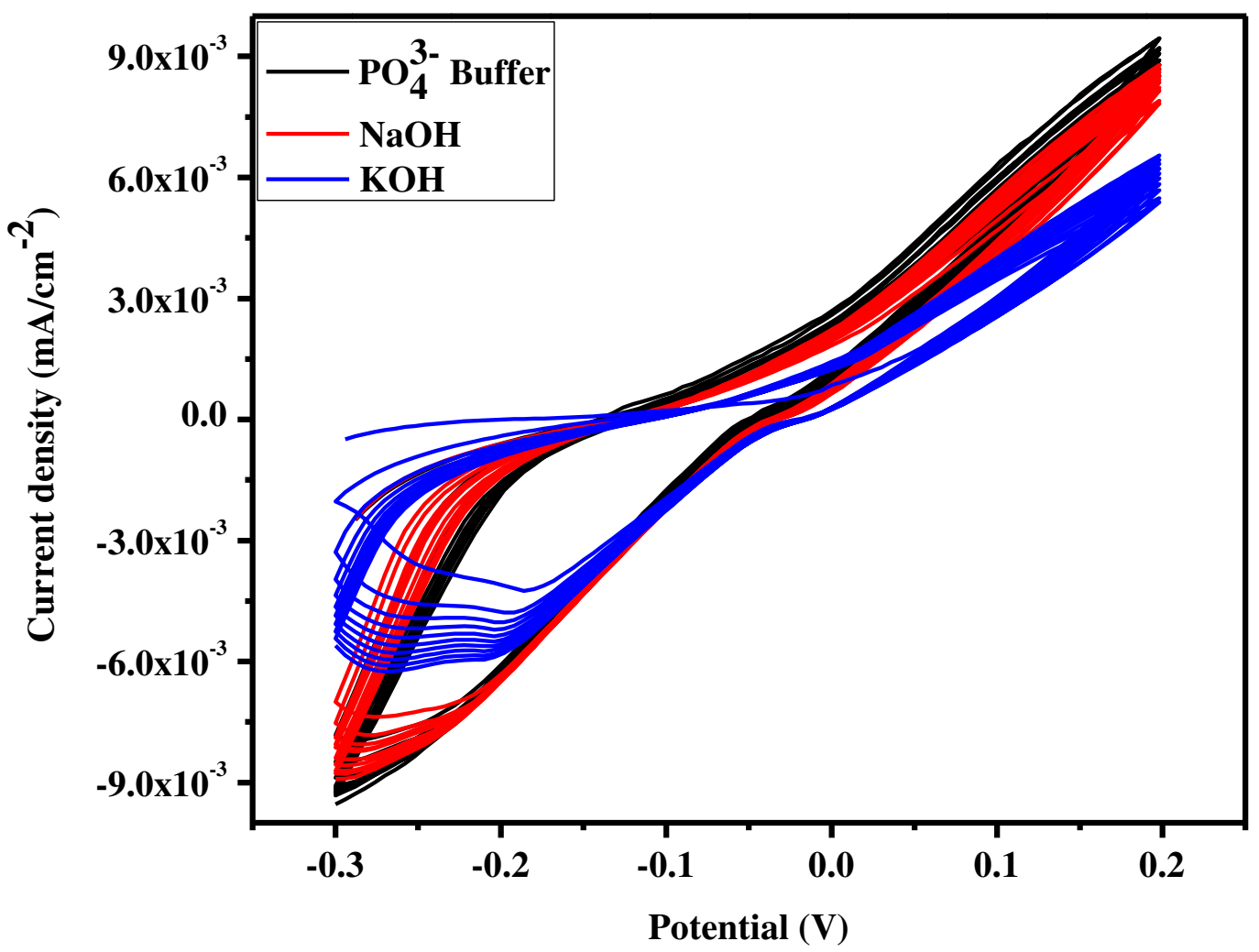

(c) 


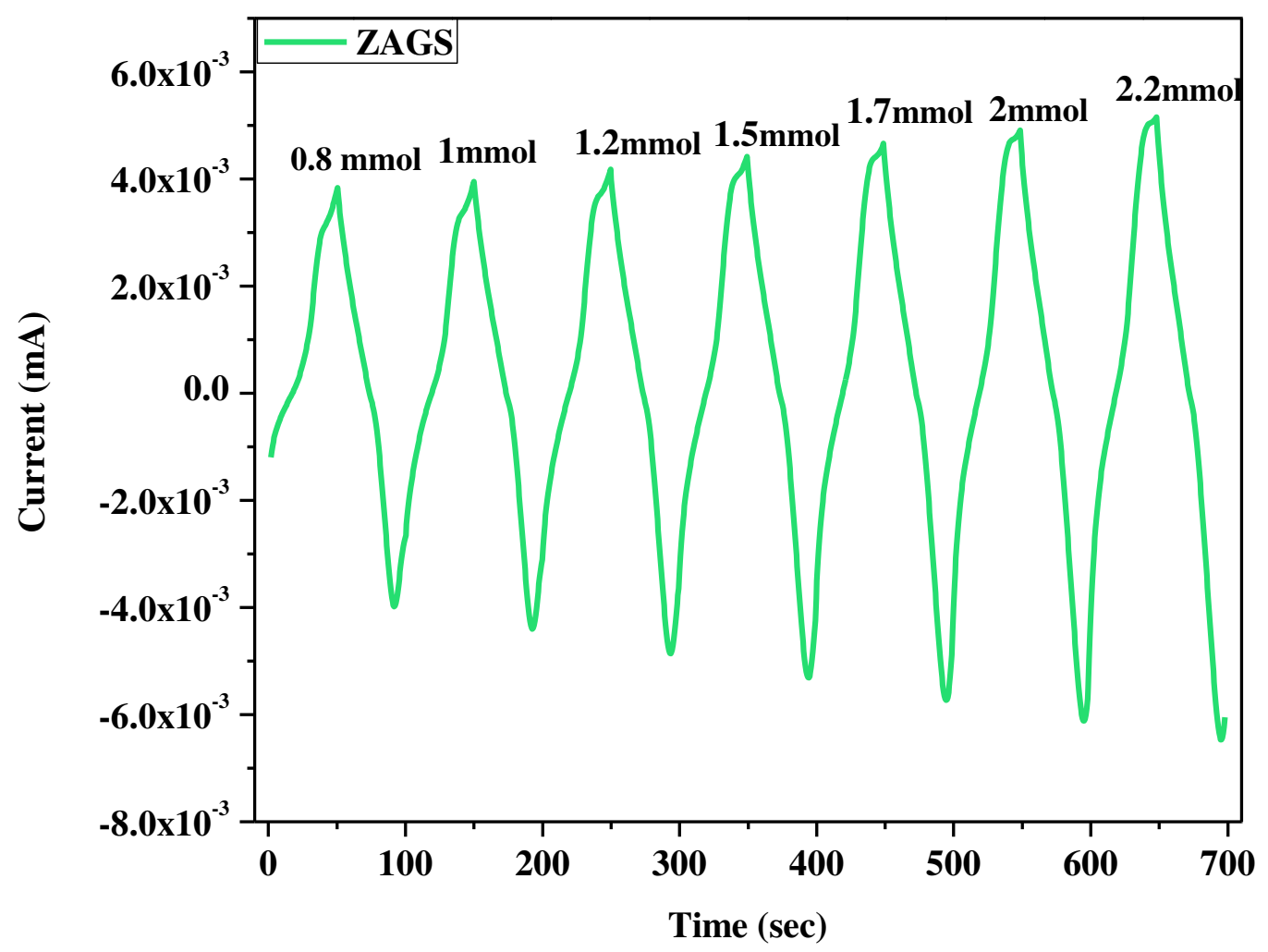

(d)

Fig. 7. (a) Cyclic voltammogram of ZS, ZA, ZAG and ZAGS electrode in urine in the absence of glucose at a scan rate of $10 \mathrm{mV} \mathrm{s}^{-1}$ (pH 7.0); (b) Cyclic voltammogram of ZS, ZA, ZAG and ZAGS sample with $0.05 \mathrm{mmol} / \mathrm{L}$ glucose in urine at scan rate of $10 \mathrm{mV} \mathrm{s}$ (pH 7.0); (c) Cyclic voltammogram of ZAGS sample with different electrolyte : $0.1 \mathrm{M}$ $\mathrm{PO}_{4}{ }^{3-}$ Buffer ( $\left.\mathrm{pH} 7.4\right) ; 0.1 \mathrm{M} \mathrm{NaOH}(\mathrm{pH} \mathrm{13})$ and $\mathrm{KOH}(\mathrm{pH} 13.5)$ at scan rate of $10 \mathrm{mV} \mathrm{s} \mathrm{s}^{-1}$ with the addition of $0.55 \mathrm{mmol} / \mathrm{L}$ glucose. (d) (i-t) curve of ZAGS sample with different conc. of glucose in $0.1 M$ PBS ( $\mathrm{pH} \mathrm{7.4).} \mathrm{All} \mathrm{experiments} \mathrm{run} \mathrm{at} \mathrm{room} \mathrm{temperature} \mathrm{(20}$ $\left.{ }^{\circ} \mathrm{C}\right)$. 


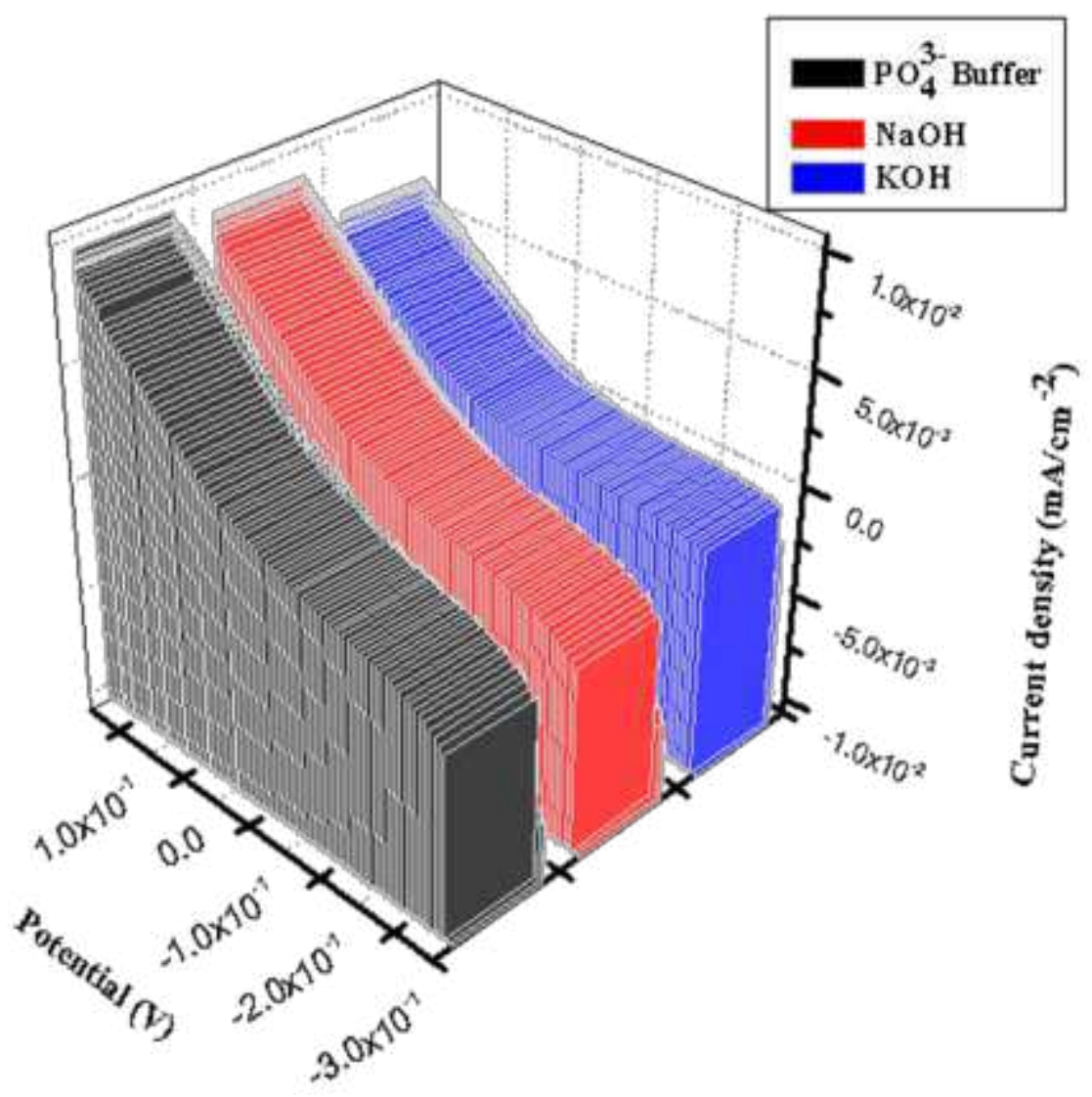

(a)

(b) 


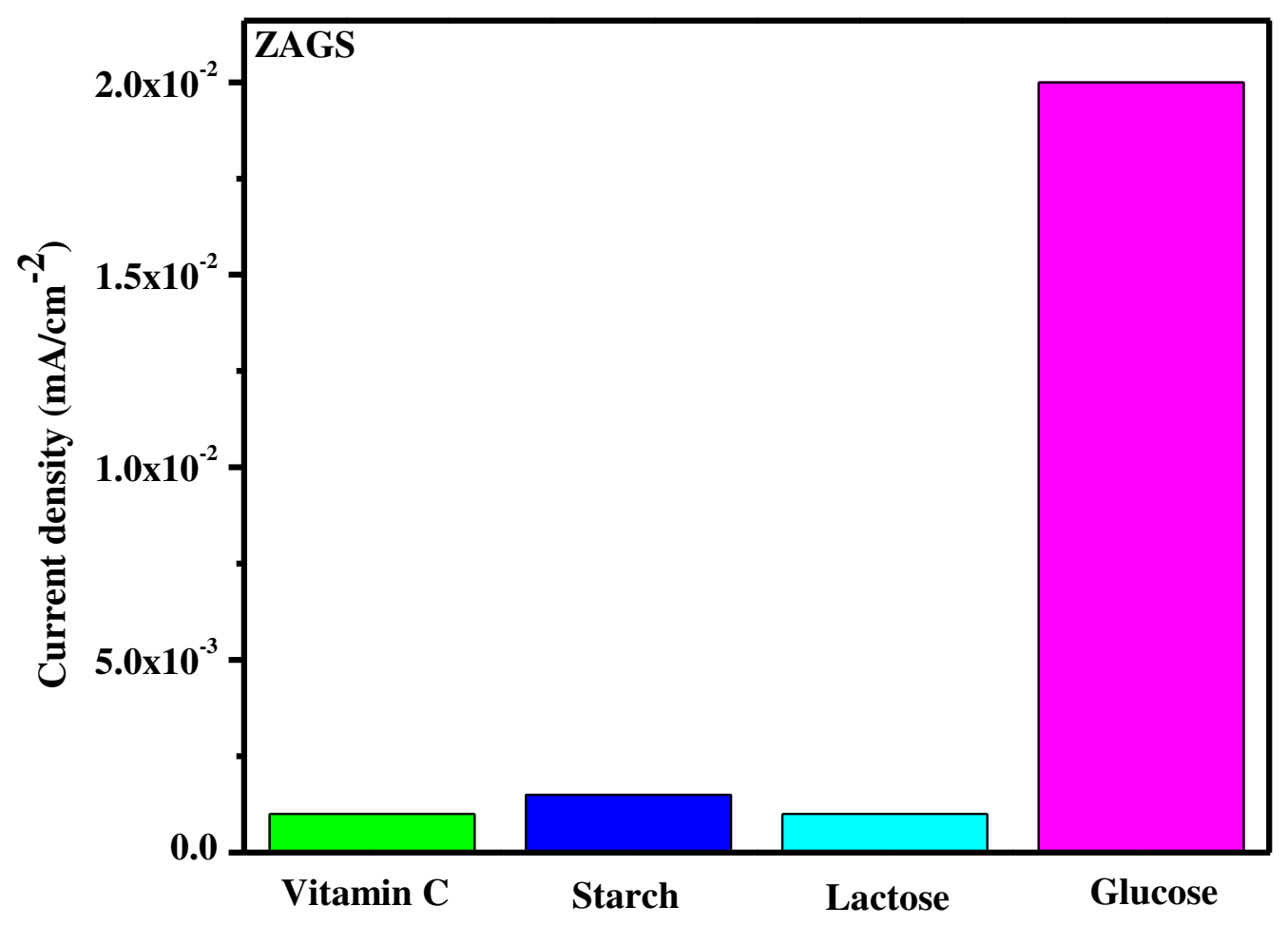

(b)

Fig. 8. (a) Sensing of glucose by ZAGS sample with different electrolytes: $0.1 \mathrm{M} \mathrm{PO}_{4}{ }^{3-}$ Buffer ( $\mathrm{pH}$ 7.4); 0.1 M NaOH ( $\mathrm{pH}$ 13) and $\mathrm{KOH}(\mathrm{pH}$ 13.5) with the addition of 0.55 $\mathrm{mmol} / \mathrm{L}$ glucose. (b) Selectivity test of glucose by the ZAGS sample with $0.91 \mathrm{mmol} / \mathrm{L}$ (Vitamin C, Starch, Lactose, Fructose, $\mathrm{NaCl}, \mathrm{KCl}$, Urea and Gucose) in $0.1 \mathrm{M}$ PBS (pH 7.4). All experiments run at room temperature $\left(20^{\circ} \mathrm{C}\right)$. 
Table 1.Surface properties obtained from nitrogen adsorption-desorption isotherms of ZAGS

\begin{tabular}{|c|c|c|c|}
\hline № & \multicolumn{3}{|c|}{ BET plot } \\
\hline 1 & Total pore volume $\left(\mathrm{cm}^{3} / \mathrm{g}\right)$ & $2.1069\left[\mathrm{~cm}^{3}(\mathrm{STP}) \mathrm{g}^{-1}\right]$ & $1.9895\left[\mathrm{~cm}^{3}(\mathrm{STP}) \mathrm{g}^{-1}\right]$ \\
\hline 2 & Surface area $\left(\mathrm{m}^{2} / \mathrm{g}\right)$ & $9.1703\left[\mathrm{~m}^{2} \mathrm{~g}^{-1}\right]$ & $8.6593\left[\mathrm{~m}^{2} \mathrm{~g}^{-1}\right]$ \\
\hline 3 & $\begin{array}{c}\text { Total pore volume } \\
(\mathrm{p} / \mathrm{p} 0=0.990)\end{array}$ & $0.020549\left[\mathrm{~cm}^{3} \mathrm{~g}^{-1}\right]$ & $0.012273\left[\mathrm{~cm}^{3} \mathrm{~g}^{-1}\right]$ \\
\hline 4 & Mean pore diameter & $8.9632 \mathrm{~nm}$ & $5.6691 \mathrm{~nm}$ \\
\hline & \multicolumn{3}{|c|}{ BJH plot } \\
\hline & \multicolumn{3}{|c|}{ ZAGS } \\
\hline 1 & $\begin{array}{c}\text { Mesopore surface area } \\
\left(\mathrm{m}^{2} / \mathrm{g}\right)\end{array}$ & $8.064\left[\mathrm{~m}^{2} \mathrm{~g}^{-1}\right]$ & $5.8875\left[\mathrm{~m}^{2} \mathrm{~g}^{-1}\right]$ \\
\hline 2 & Mesopore volume $\left(\mathrm{cm}^{3} / \mathrm{g}\right)$ & $0.01969\left[\mathrm{~cm}^{3} \mathrm{~g}^{-1}\right]$ & $0.011075\left[\mathrm{~cm}^{3} \mathrm{~g}^{-1}\right]$ \\
\hline 3 & Average mesopore diameter & $3.77 \mathrm{~nm}^{2}$ & $3.77 \mathrm{~nm}^{2}$
\end{tabular}


Figures

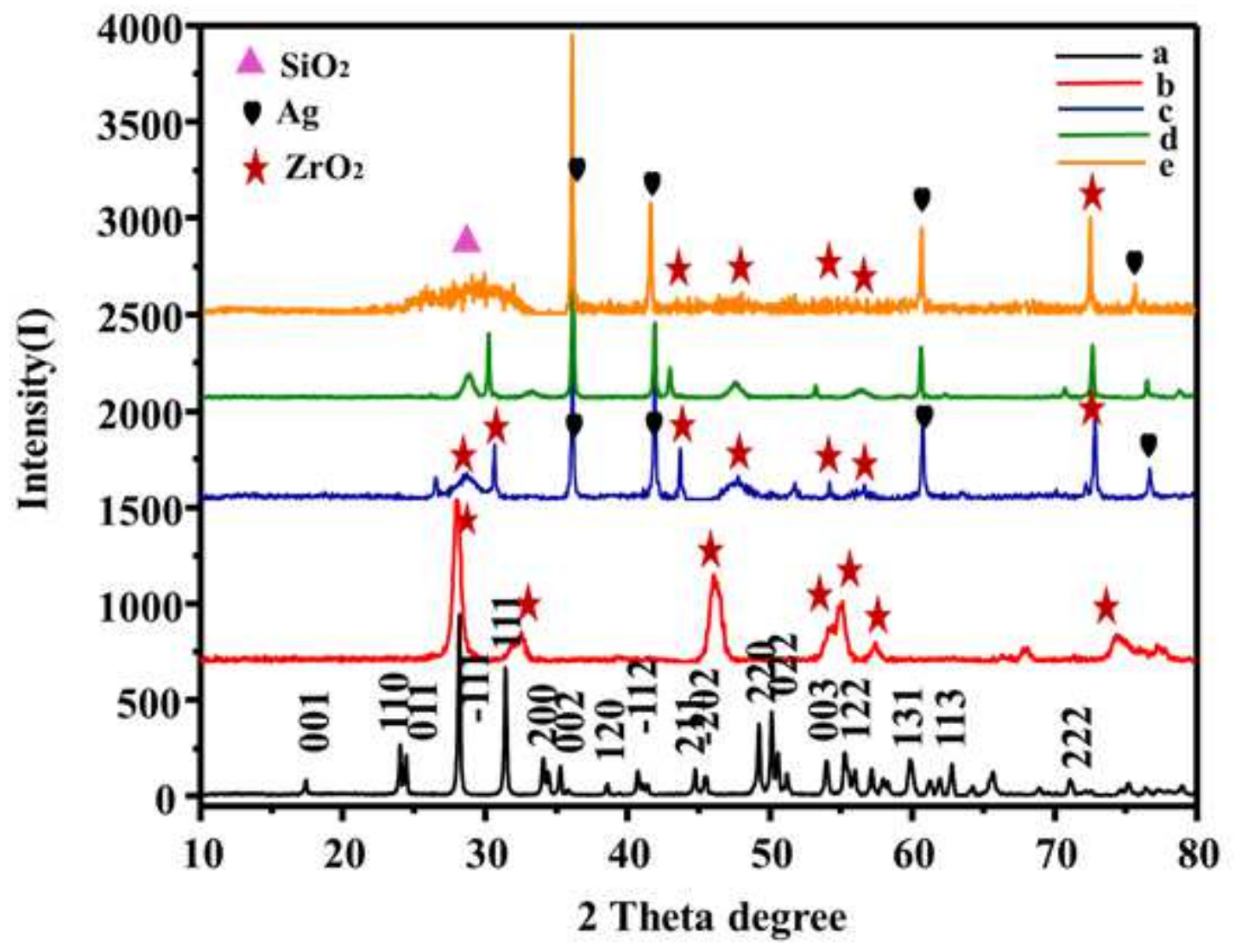

Figure 1

XRD patterns of ZC (a), ZS (b), ZA(c), ZAG (d) and ZAGS (e). 

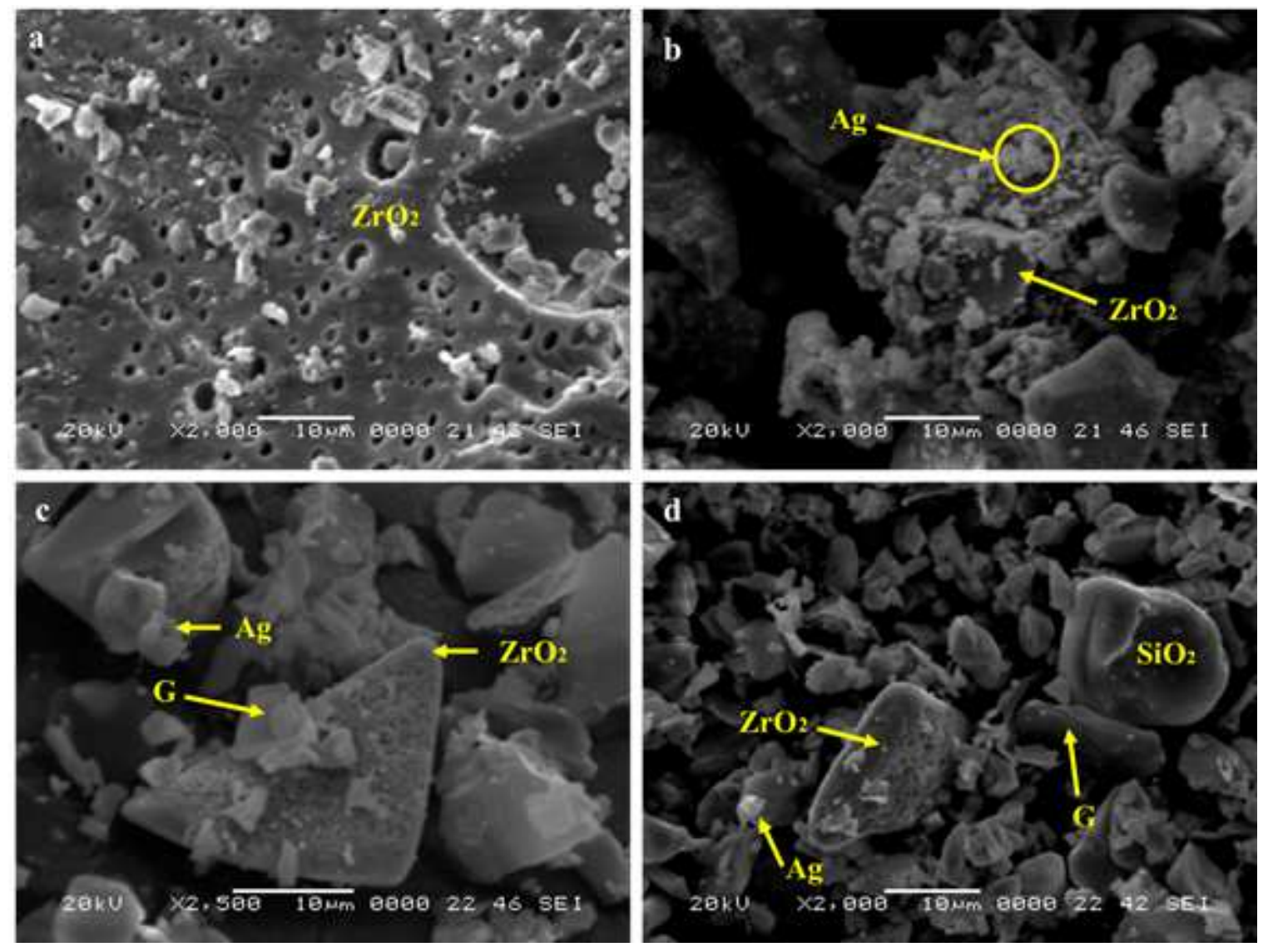

Figure 2

SEM images of ZS, ZA, ZAG and ZAGS. 


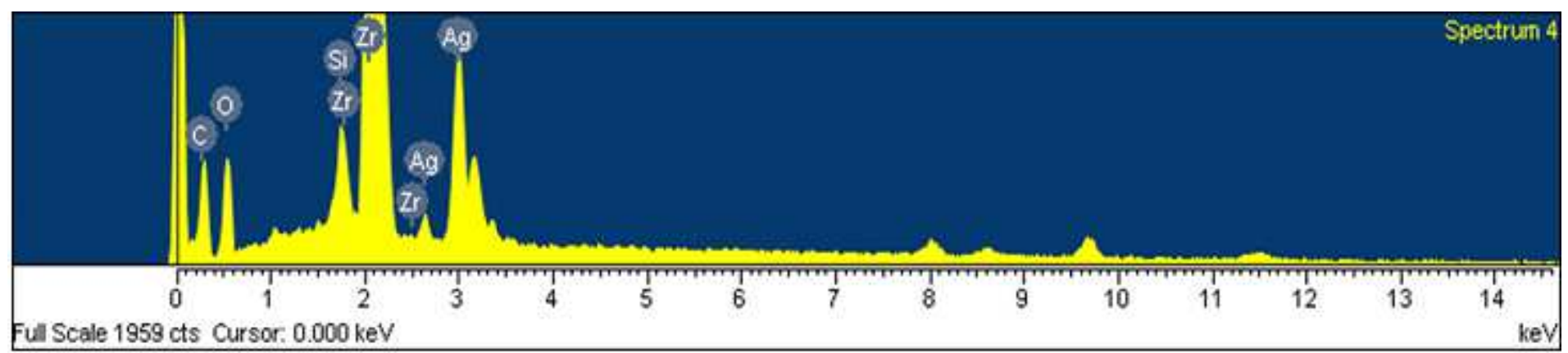

\section{Quantitative results}

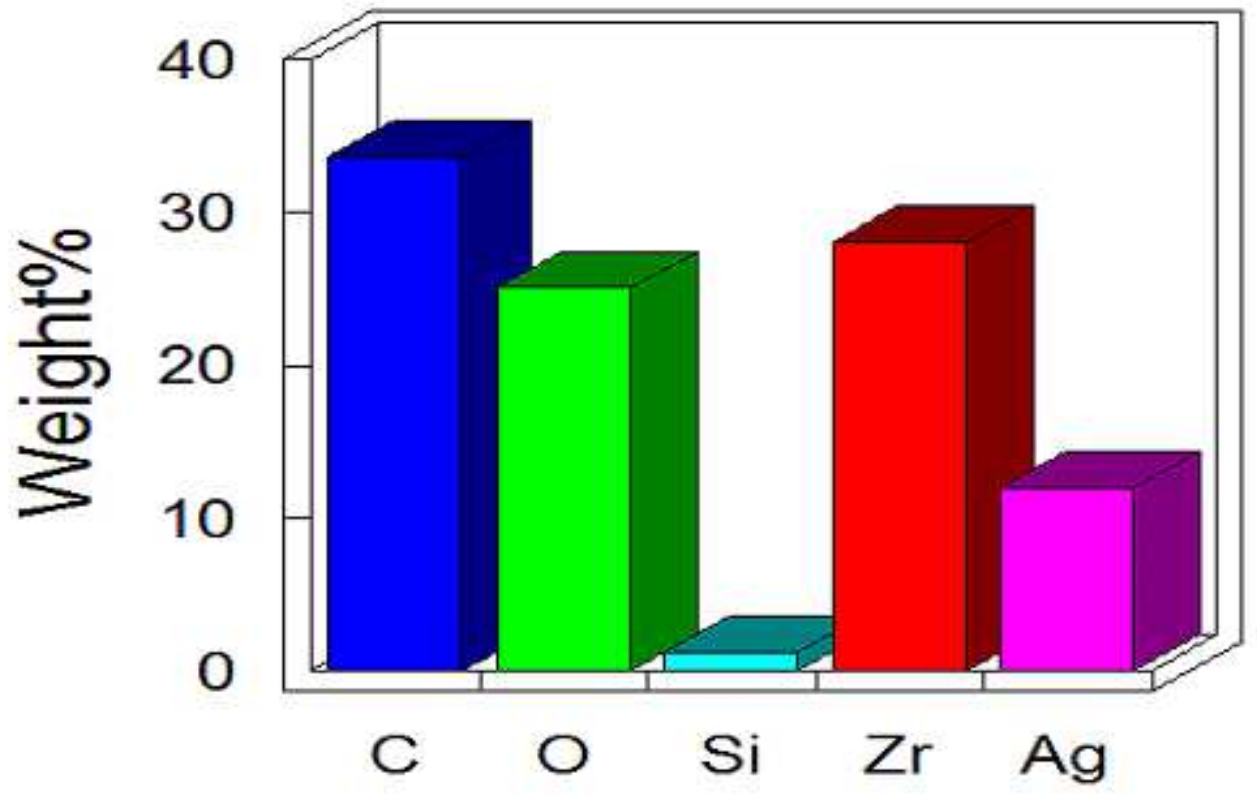

Figure 3

EDS of ZAGS Samples. 

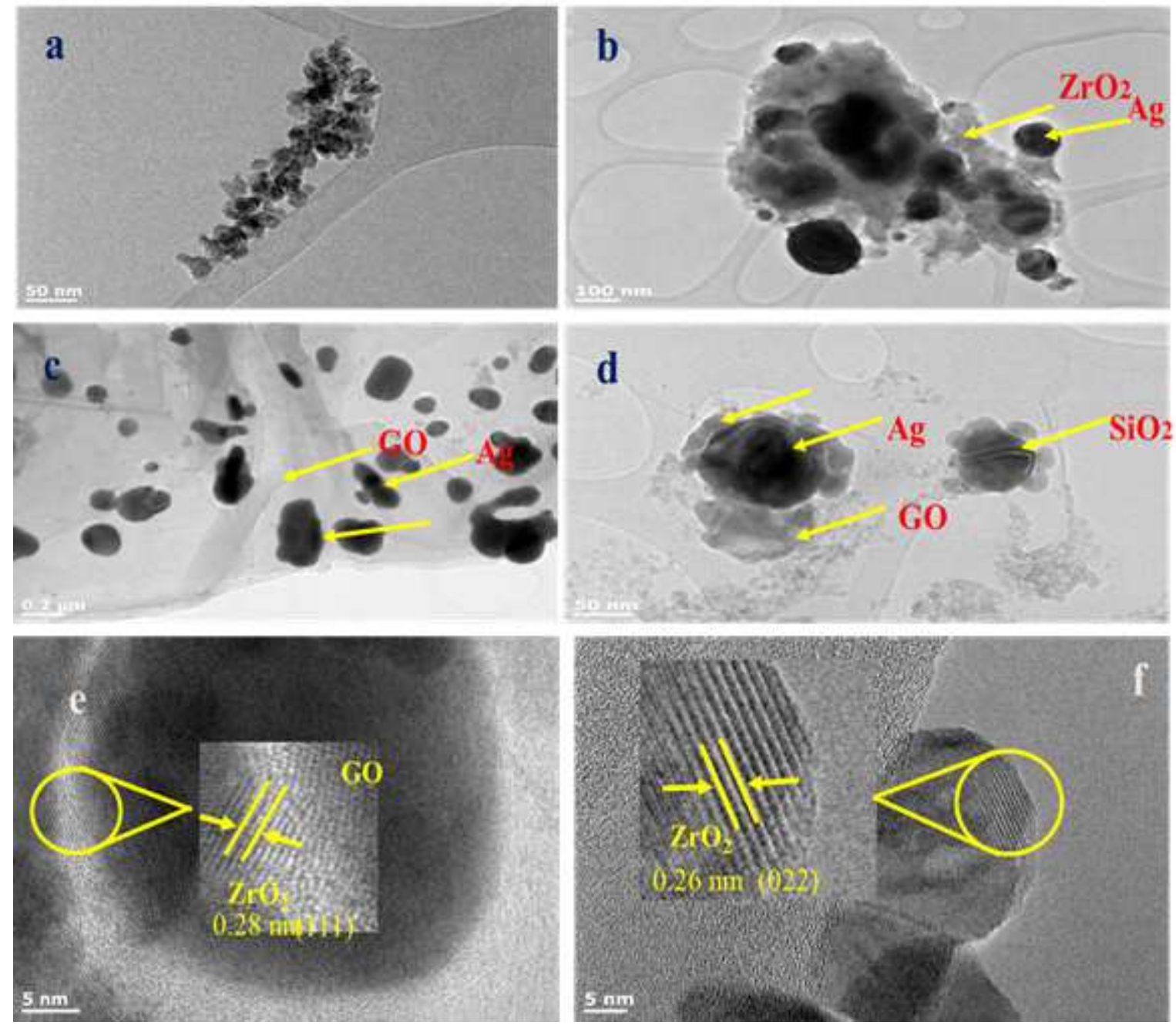

Figure 4

TEM Images of ZS (a) ZA (b); ZAG(c); ZAGS (d) and HRTEM Images of ZS (e) ZAGS (f). 

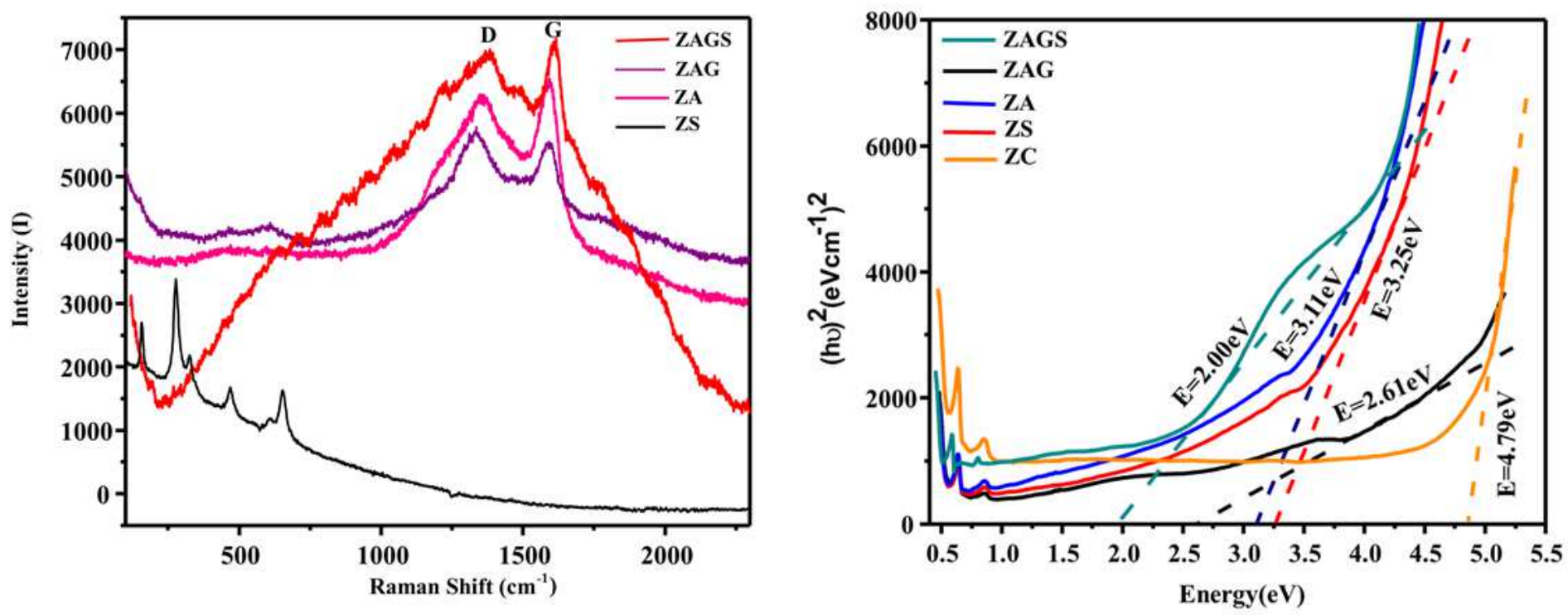

(b)

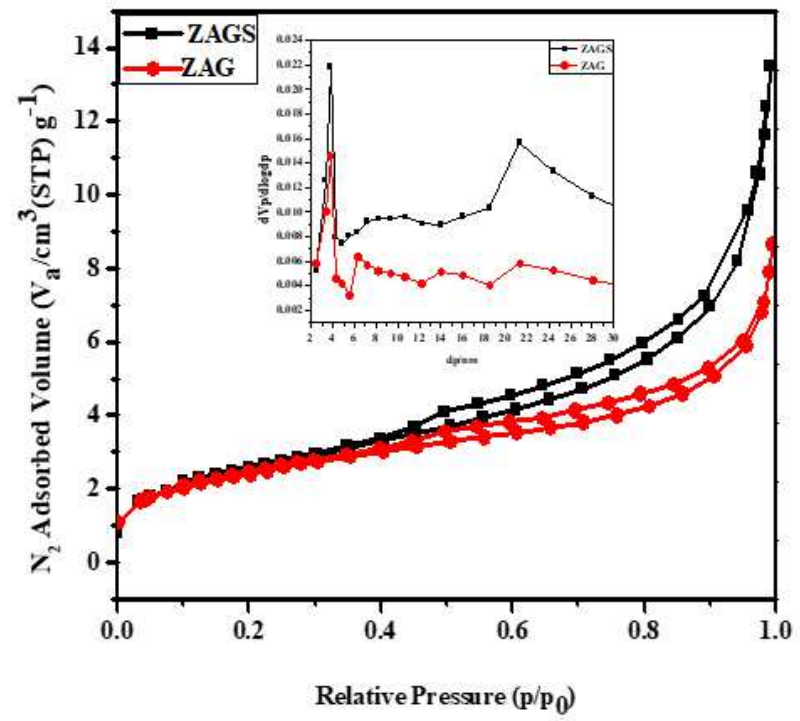

(c)

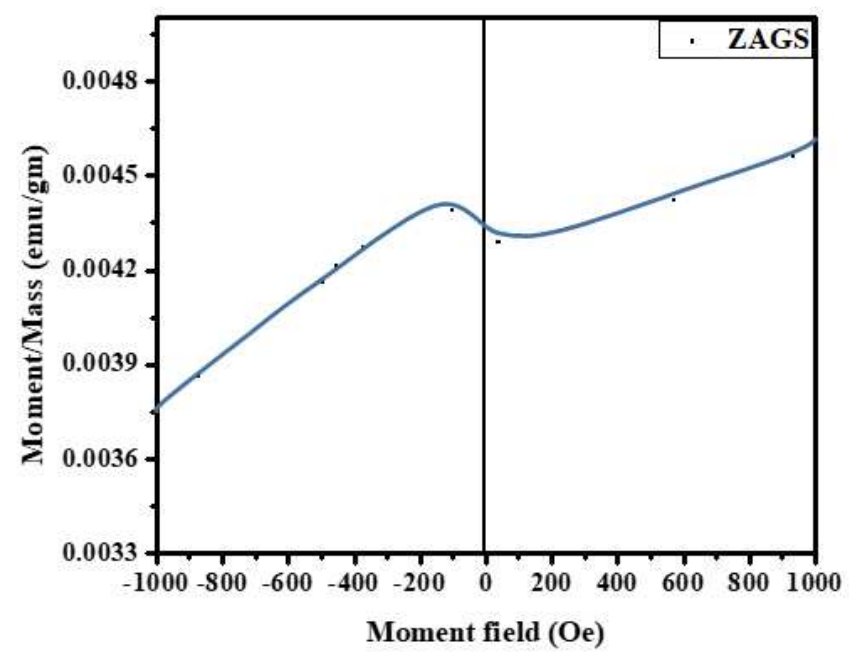

(d)

Figure 5

(a) Raman spectra of ZS, ZA, ZAG and ZAGS sample, (b) Nitrogen adsorption-desorption isotherms of ZAG, ZAGS; and the corresponding pore size distributions (inset), (c) DRS data of ZC, ZS, ZA, ZAG, ZAGS and (d) Magnetic field area of ZAGS. 

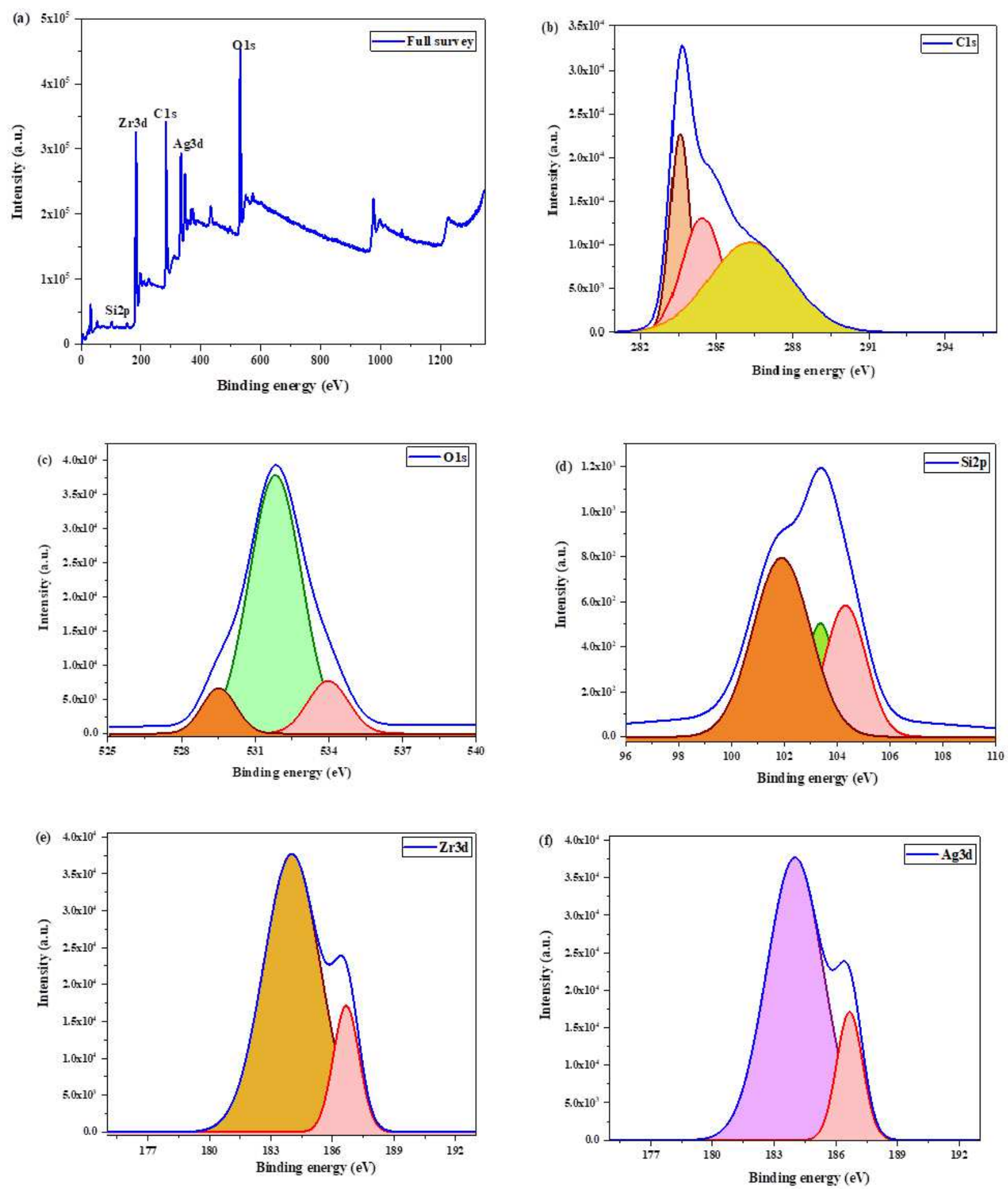

\section{Figure 6}

XPS spectra of ZAGS (a) survey, C1s (b), Si2p (c), Zr3d (d), 01s (e) and Ag3d (f). 


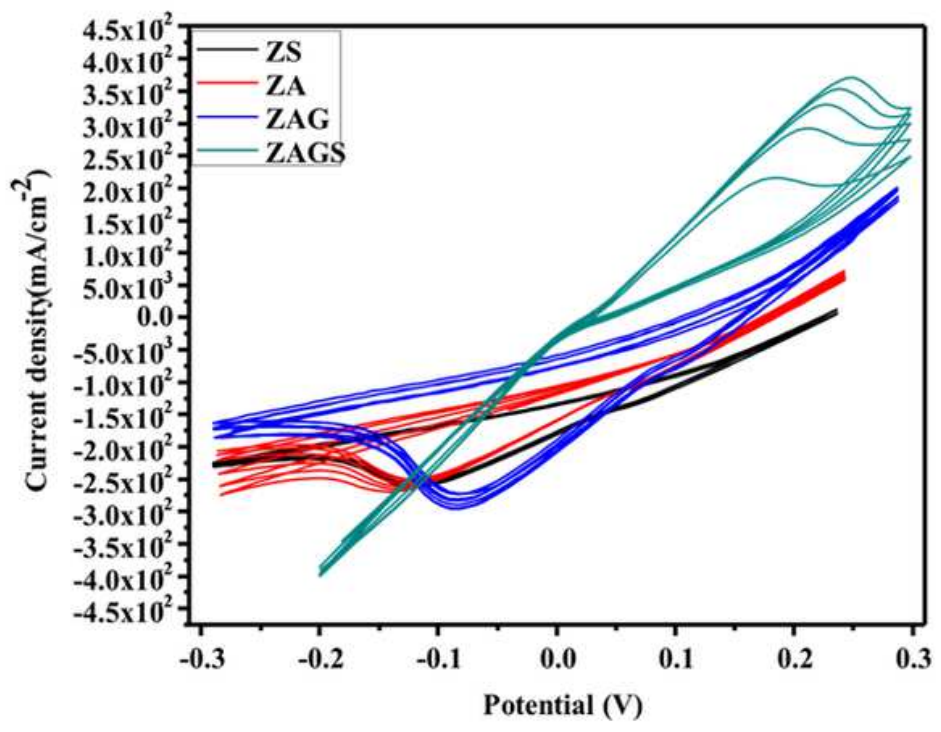

(a)

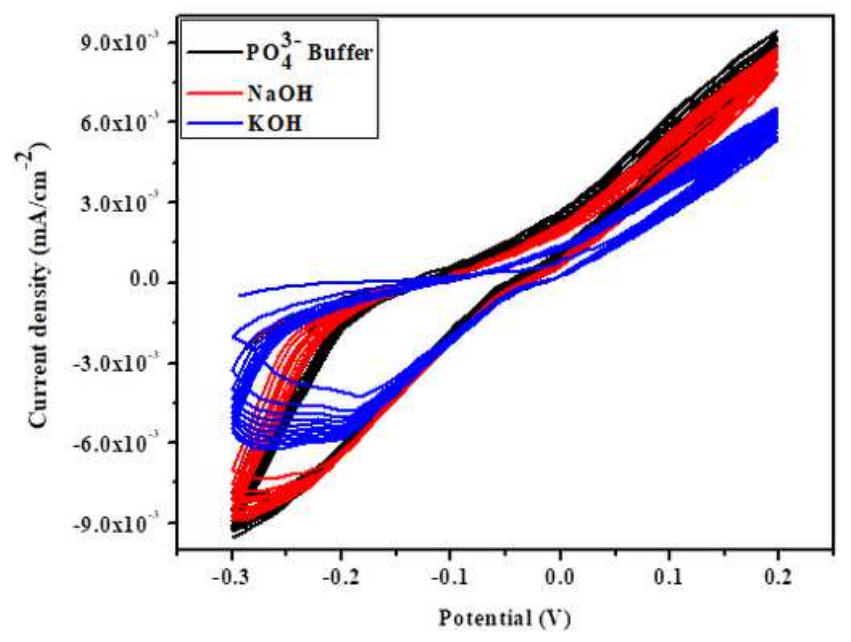

(c)

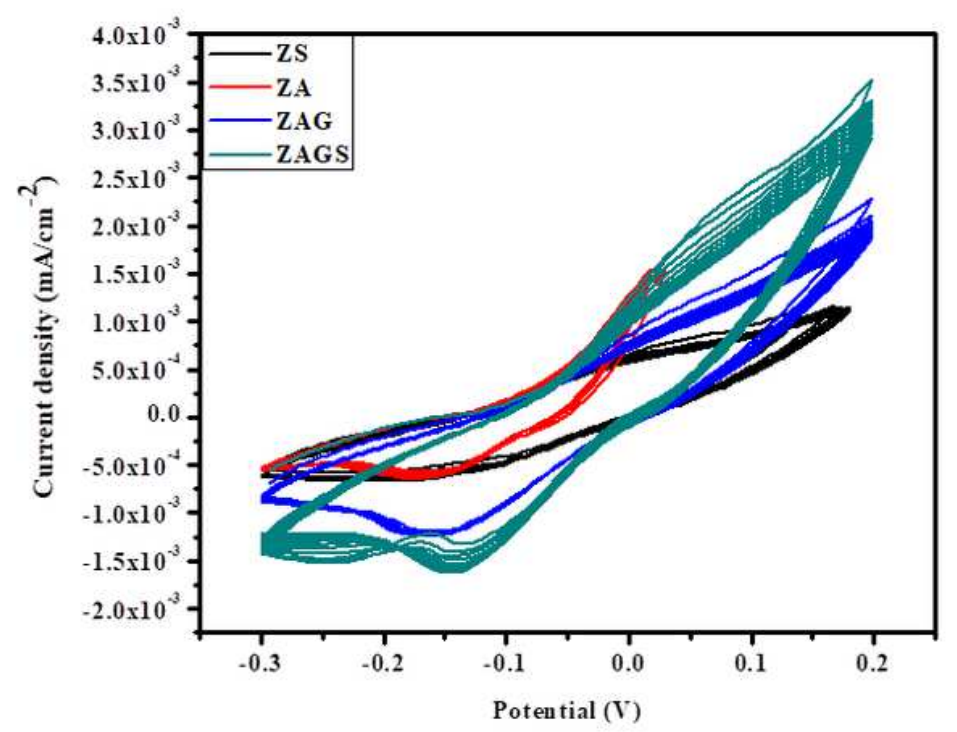

(b)

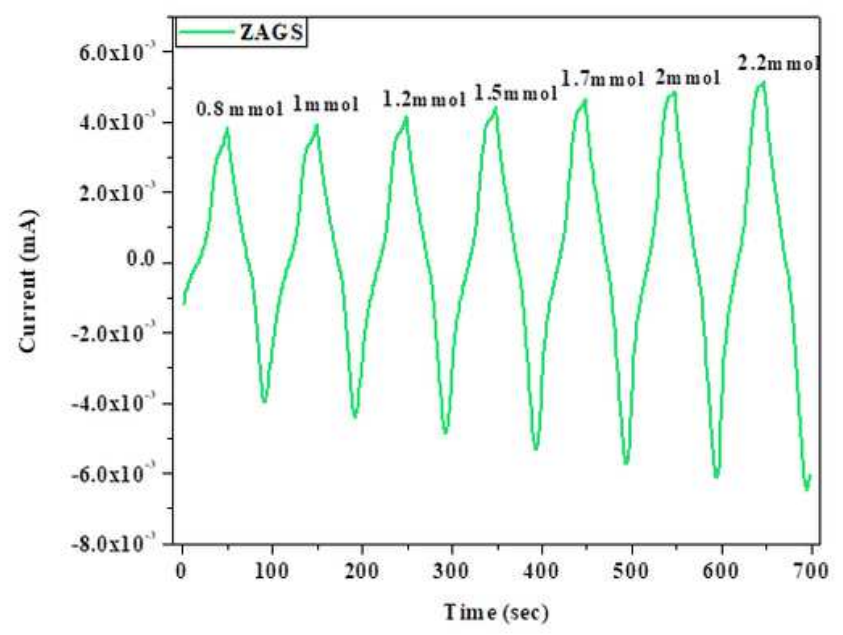

(d)

\section{Figure 7}

(a) Cyclic voltammogram of ZS, ZA, ZAG and ZAGS electrode in urine in the absence of glucose at a scan rate of $10 \mathrm{mV} \mathrm{s}-1$ (pH 7.0); (b) Cyclic voltammogram of ZS, ZA, ZAG and ZAGS sample with $0.05 \mathrm{mmol} / \mathrm{L}$ glucose in urine at scan rate of $10 \mathrm{mV} \mathrm{s}-1$ (pH 7.0); (c) Cyclic voltammogram of ZAGS sample with different electrolyte : 0.1 M PO43-Buffer ( $\mathrm{pH} 7.4) ; 0.1 \mathrm{M} \mathrm{NaOH}(\mathrm{pH} 13)$ and $\mathrm{KOH}(\mathrm{pH} 13.5)$ at scan rate of $10 \mathrm{mV} \mathrm{s}-1$ with the addition of $0.55 \mathrm{mmol} / \mathrm{L}$ glucose. (d) (i-t) curve of ZAGS sample with different conc. of glucose in $0.1 \mathrm{M} \mathrm{PBS}(\mathrm{pH} 7.4)$. All experiments run at room temperature $\left(20^{\circ} \mathrm{C}\right)$. 


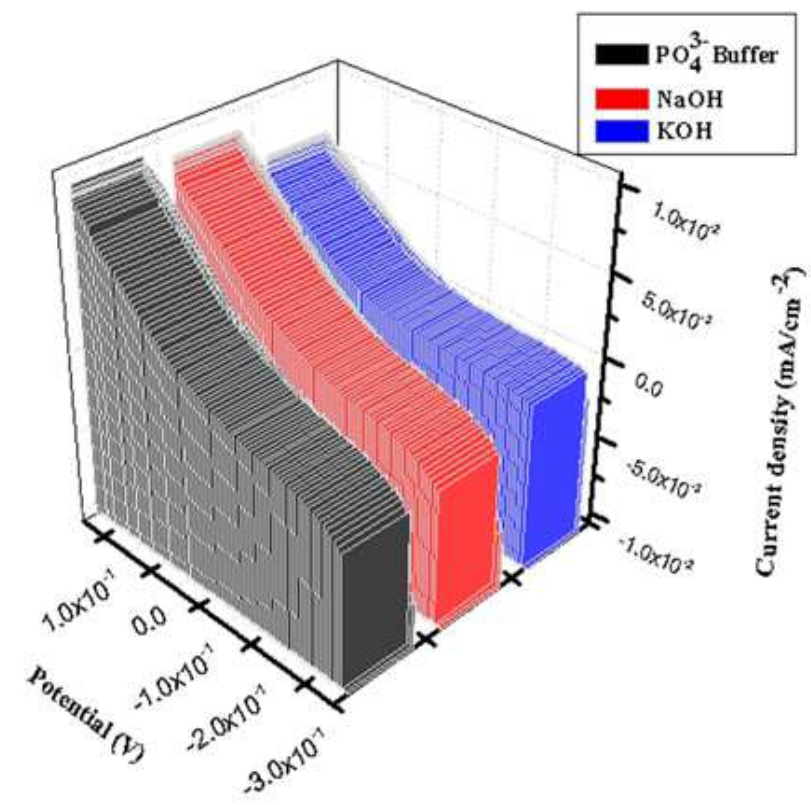

(a)

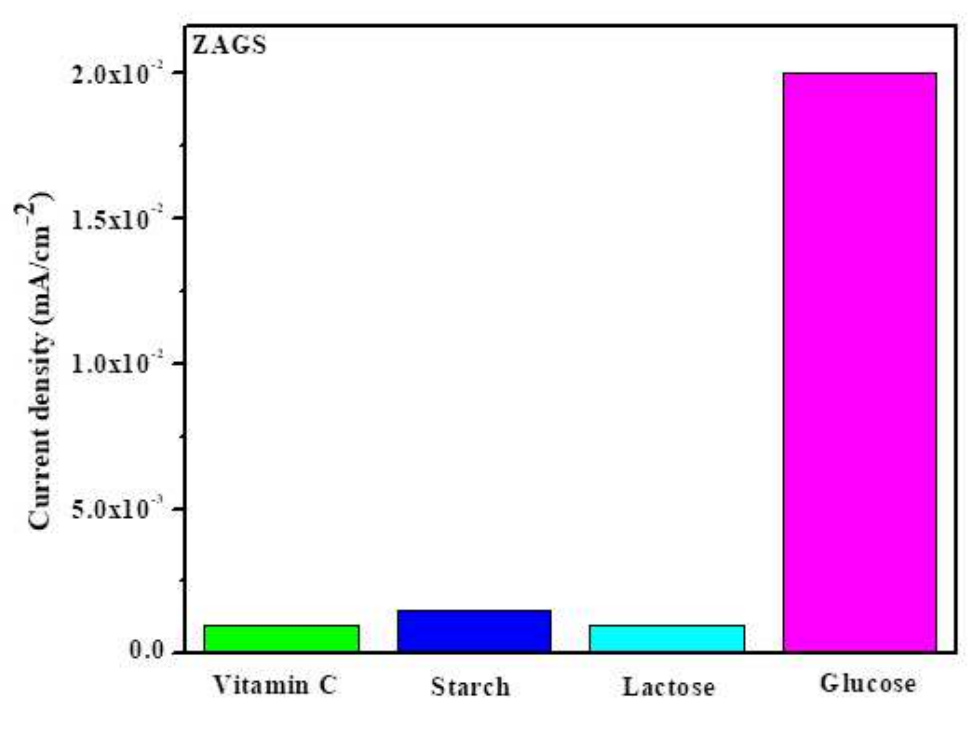

(b)

\section{Figure 8}

(a) Sensing of glucose by ZAGS sample with different electrolytes: $0.1 \mathrm{M}$ P043-Buffer (pH 7.4); $0.1 \mathrm{M}$ $\mathrm{NaOH}(\mathrm{pH} \mathrm{13})$ and $\mathrm{KOH}(\mathrm{pH}$ 13.5) with the addition of $0.55 \mathrm{mmol} / \mathrm{L}$ glucose. (b) Selectivity test of glucose by the ZAGS sample with $0.91 \mathrm{mmol} / \mathrm{L}$ (Vitamin C, Starch, Lactose, Fructose, $\mathrm{NaCl}, \mathrm{KCl}$, Urea and Gucose) in $0.1 \mathrm{M} \mathrm{PBS}(\mathrm{pH} 7.4)$. All experiments run at room temperature $\left(20^{\circ} \mathrm{C}\right)$. 